\author{
Mar/2020 \\ Working Paper 20-07 \\ rcea.org/RePEc/pdf/wp20-07.pdf
}

\title{
THE POLITICAL (IN)STABILITY OF FUNDED PENSION SYSTEMS
}

\author{
Roel Beetsma \\ University of Amsterdam, Netherlands \\ European Fiscal Board \\ Oliwia Komada \\ FAME|GRAPE \\ Warsaw School of Economics, Poland \\ Krzysztof Makarski \\ FAME|GRAPE \\ Warsaw School of Economics, Poland
Joanna Tyrowicz
FAME|GRAPE
IOS \\ University of Warsaw, Poland \\ IZA \\ RCEA
}

Copyright belongs to the author. Short sections of the text, not exceeding three paragraphs, can be used provided proper acknowledgement is given.

The Rimini Centre for Economic Analysis (RCEA) was established in March 2007. RCEA is a private, nonprofit organization dedicated to independent research in Applied and Theoretical Economics and related fields. RCEA organizes seminars and workshops, sponsors a general interest journal, the Review of Economic Analysis (REA), and organizes a biennial conference, the Rimini Conference in Economics and Finance (RCEF). Scientific work contributed by the RCEA Scholars is published in the RCEA Working Paper series.

The views expressed in this paper are those of the authors. No responsibility for them should be attributed to the Rimini Centre for Economic Analysis. 


\title{
The political (in)stability of funded pension systems*
}

\author{
Roel Beetsma ${ }^{\dagger} \quad$ Oliwia Komada ${ }^{\ddagger} \quad$ Krzysztof Makarski $^{\S} \quad$ Joanna Tyrowicz $^{\uparrow}$
}

March 2020

\begin{abstract}
We analyze the political stability of capital funded social security. In particular, using a stylized theoretical framework we study the mechanisms behind governments capturing pension assets in order to lower current taxes. This is followed by an analysis of the analogous mechanisms in a fully-fledged overlapping generations model with intra-cohort heterogeneity. Funding is efficient in a Kaldor-Hicks sense. Individuals vote on capturing the accumulated pension assets and replacing the funded pension pillar with a pay-as-you-go scheme. We show that even if capturing assets reduces welfare in the long run, it always has sufficient political support from those alive at the moment of the vote.
\end{abstract}

Key words: funded pensions, asset capture, majority voting, welfare.

JEL Codes: H55, D72, E17, E27

${ }^{*}$ Thomas Apolte, Monika Bütler, Damiaan Chen, Nicoleta Ciurila, Hans Fehr, Vincenzo Galasso, Christian Geppert, Nezih Guner, Ward Romp, Jan-Egbert Sturm and participants in a Netspar Workshop, the Netspar International Pension Day, the Royal Economic Society Annual Meeting and the European Public Choice Society Annual Meeting all provided extremely useful comments on an earlier version. We are also grateful for remarks from participants of seminars at the National Bank of Poland, GRAPE, the University of Warsaw and the Warsaw School of Economics. The authors are grateful for research assistance to Marcin Bielecki and Magda Malec, whose work was supported within a National Science Center grant \# 2012/01/D/HS4/04039. The authors' work was graciously supported by National Science Center grant \# 2014/13/B/HS4/03264. All opinions expressed are those of the authors and do not necessarily coincide with those of the National Science Center, European Fiscal Board or any other institution they are affiliated with. Any remaining errors are ours.

${ }^{\dagger} \mathrm{MN}$ Chair in Pension Economics, University of Amsterdam and European Fiscal Board, r.m.w.j.beetsma@uva.nl.

${ }^{\ddagger}$ FAME|GRAPE, Warsaw School of Economics, o.komada@grape.org.pl.

${ }^{\S}$ FAME|GRAPE, Warsaw School of Economics, k.makarski@grape.org.pl.

`FAME|GRAPE, IOS, University of Warsaw and IZA, j.tyrowicz@grape.org.pl (corresponding author). 


\section{Introduction}

Political support for social security has been extensively studied in the literature with key questions encompassing the very existence of inter-generational transfers (e.g. Samuelson 1958, Aaron 1966, Breyer 1989, Boll et al. 1994, Krieger and Ruhose 2013), the size of these transfers (e.g. Browning 1975, Boldrin and Rustichini 2000, Casamatta et al. 2001), and the political economy of arriving at a social contract (e.g. Sjoblom 1985, Boadway and Wildasin 1989a,b, Cooley and Soares 1996, 1999a,b, Tabellini 2000, Conde-Ruiz and Galasso 2005, Kelley 2014, Parlevliet 2017). This literature typically refers to social security as a pay-as-you-go (PAYG) transfer from current workers to the retired. The findings in this literature have been synthesized in different review studies (Galasso and Profeta 2002, de Walque 2005, Mulligan and Sala-i Martin 2015) that conclude that PAYG social security can be a politically stable arrangement. This typically relies on the assumption that if a working generation refuses to pay its transfer, it will not receive a transfer from the next working generation once it is old, causing the arrangement to be permanently dismantled.

However, pensions do not need to be financed on a PAYG basis. The alternative is a funded system in which the participants save for their own pension. The political stability of such a system cannot rely on the retaliation mechanism described above. The contribution of this paper is the analysis of the political stability of funded pension systems. This is of particular relevance in view of the developments in a number of countries that introduced (partial) funding between the mid-1990s and early 2000s (see Holzman and Stiglitz 2001, Bonoli and Shinkawa 2006, Gruber and Wise 2009). Most of these countries originally had a defined-benefit (DB) Beveridge type of system financed on a PAYG basis. Reform implied the replacement of these systems with an individual defined-contribution (DC) Bismarckian system combining mandatory publicly-managed PAYG and privately-managed funded pillars. ${ }^{1}$ These reforms were supposed to deliver long-run welfare gains, even when accounting for the transition costs, i.e. they would improve welfare in the Kaldor-Hicks sense. ${ }^{2}$

However, a decade or so after these reforms were introduced, they were rolled back with governments expropriating the assets accumulated in the funded pillar, thereby reducing or eliminating this pillar, while raising the share of contributions going to the PAYG pillar (Schwarz 2011, Schwartz 2014). ${ }^{3}$ Although these policy reversals are projected to reduce future pension benefits (by roughly 10-20\%, see Jarrett 2011, Hagemejer et al. 2015, for Slovakia and Hungary, and Poland, respectively), surprisingly they have been politically feasible. Our analysis explains these reversals as the result of a majority of the living cohorts on net benefitting from the fact that the tax reductions financed by appropriating the pension assets dominate the reduction in future pensions caused by the shift from funded DC to PAYG-DC. This shift occurs irrespective of the future moment at which the vote takes place and is robust against the presence of substantial within-cohort heterogeneity.

We construct an overlapping-generations general-equilibrium framework, in which individuals pe-

\footnotetext{
${ }^{1}$ In addition, voluntary funded pillars were established with tax incentives to encourage private savings for retirement.

${ }^{2}$ A study for Poland shows that these welfare gains can be sizable, on the order of $2-3 \%$ of lifetime consumption (Makarski et al. 2017). Without exception these reforms honored the pension obligations to the transition cohorts, i.e. those already retired or too close to retirement to meaningfully adjust to the new situation. They also kept overall contribution rates unchanged. The result was a fiscal gap, as current pensions were paid in full, while at the same time part of the collected contributions were channeled to the funded pillar. The benefit of the reforms was enhanced efficiency by establishing a link between labor supply and future pension benefits and by promoting capital accumulation.

${ }^{3}$ However, none of these countries abandoned the DC feature of their pension systems.
} 
riodically vote whether to maintain the funded pillar of their universal pension system, or whether the government should appropriate the assets from the funded pillar in order to reduce taxes and translate the existing funded pillar entitlements into drawing rights in the PAYG pillar. As the return on the funded pillar exceeds that of the PAYG pillar, individuals in effect face a trade off between lower future pensions and lower current taxes. The overall benefit will in addition be affected by the general equilibrium effects associated with adjustments in the labor supply, private voluntary savings and life-time consumption profiles. ${ }^{4}$ Unlike the earlier literature, we also compare a vote to permanently dismantle the funded pillar with one to temporarily appropriate pension assets. The distribution of the benefits and costs of the asset capture differs across the cohorts currently alive. In particular, younger cohorts at the moment of the vote forego more of the higher return on funded pension contributions. However, for both a permanent dismantling of the funded pillar and a temporary asset capture we demonstrate that the tax reduction channel dominates the pension reduction channel for a majority the voters at any point in time. Hence, in line with the experience of a number of countries in Central and Eastern Europe, our overall conclusion is that a funded pension pillar is politically not stable if the alternative of a PAYG pillar is available.

Our paper relates to the literature on "privatizing social security", which tends to emphasize (Hicksian) welfare improvement. ${ }^{5}$ There, the key policy challenge is the appropriate timing of the introduction of funding, because the working cohorts have to finance the pensions of both their predecessors and themselves (Huang et al. 1997). This double burden may be ameliorated by deploying public debt to smooth the costs of the reform across cohorts (Belan and Pestieau 1999, Song et al. 2015, Makarski et al. 2017). This also matters from a political perspective, because a transfer of future welfare gains helps to compensate the current losses of the transition cohorts that need to support the reform (Conesa and Garriga 2008, compare various ways to introduce a funded pillar with political support). While this literature analyzes the political economy of introducing funded social security, to the best of our knowledge there exists little or no work on whether a funded pillar, once introduced, is politically stable.

The remainder of our paper is structured as follows. In Section 2 we demonstrate our main results in a stylized three-period model. Section 3 presents our quantitative overlapping generations model, while Section 4 describes the calibration and the policy options we will analyse. To relate our analysis to recent policy changes, the economy and pension system are calibrated to the case of Poland. In 1999 the country reformed its PAYG-DB system into a two-pillar DC scheme, which combined a PAYG with a funded pillar. In 2011 it started shifting contributions from the funded to the PAYG pillar, while in 2013 part of the assets in the funded pillar were nationalized. In this regard, Poland is a rather exemplary case for Central and Eastern Europe. Section 5 discusses the results. Finally, Section 6 concludes the paper.

\footnotetext{
${ }^{4}$ Note that this problem is analogous, au rebours, to the introduction of a funded pillar in an economy with PAYG pensions. Introducing a funded pillar yields delayed gains in the form of higher pensions and lower future taxes, but at the expense of a contemporaneous increase in taxation. Here, the gains from capturing the assets are immediate, whereas the costs in terms of lower pensions are born later.

${ }^{5}$ The general conclusion of welfare gains is a robust finding, see a discussion by Conesa and Krueger (1999), Fehr (2009).
} 


\section{$2 \quad$ A stylized illustrative model}

This section presents a simple theoretical model to explore whether a pension system with a funded pillar is politically sustainable. The system also features a PAYG pillar. We assume an open economy with endogenous savings and a single asset earning an exogenous and constant interest rate $r$. Voters decide whether to retain the complete pension system, whether to dismantle only the funded part or whether to dismantle the entire pension system. The next section presents a fully-fledged quantitative model that features the same possible voting outcomes, but allows for intra-cohort heterogeneity and general equilibrium effects.

\section{$2.1 \quad$ Environment}

Our economy is populated by overlapping generations of individuals who live for $J=3$ periods. Cohorts of newborns are of equal size in each period and, hence, the population and its demographic structure are constant over time. We normalize the size of a cohort of newborns to 1 . Within each cohort individuals are identical. In the first two periods of their life, individuals work for an exogenous real wage $w$, which grows at a constant rate $g$. In the third period of their life they are retired and at the end of this period they die. Without loss of generality, there is no mortality risk during the first two periods of their life. We allow for an individual life span of three periods in order to have meaningful majority votes over alternative policies.

The preferences of an individual born in period $t$ are

$$
\mathcal{U}_{t}=\sum_{j=1}^{J} \delta^{j-1} u\left(c_{j, t+j-1}\right)
$$

where $c_{j, t+j-1}$ denotes the period $t+j-1$ consumption of an individual in period $j$ of her life and $u(\cdot)$ is strictly increasing and strictly concave. Individuals inelastically supply one unit of labor in each of the first two periods of their life and are retired in the third period of their life. Their income $\Psi_{j, t}$ in period $j$ originates either from labor earnings $(j<J)$ or a pension benefit $b_{j, t}(j=J)$ :

$$
\Psi_{j, t}= \begin{cases}(1-\tau) w_{t}, & \text { for } j<J \\ b_{j, t}, & \text { otherwise }\end{cases}
$$

where $\tau$ denotes social security contributions. Individuals can accumulate assets $a_{j, t}$ in order to smooth consumption over their lifetime. The budget constraint of an individual of age $j$ in period $t$ is given by

$$
a_{j+1, t+1}+c_{j, t}+\Upsilon_{t}=(1+r) a_{j, t}+\Psi_{j, t}
$$

where $\Upsilon_{t}$ is a lump-sum tax.

For pensions we consider a system with a PAYG and a funded pillar. The contributions at a rate $\tau^{P}$ to the PAYG pillar are indexed at the growth rate of the economy's wage bill, which is the same as the growth rate $g$ of the individual wage rate, because the working-age population is constant, while the contributions at a rate $\tau^{F}$ to the funded pillar are invested against the interest rate $r$. Thus, 
individuals accumulate entitlements and funds in both pillars according to the following formulas:

$$
\begin{aligned}
\text { PAYG entitlements: } & f_{j+1, t+1}^{P}=(1+g)\left(f_{j, t}^{P}+\tau_{t}^{P} w_{t}\right) \\
\text { Assets in funded pillar: } & f_{j+1, t+1}^{F}=(1+r)\left(f_{j, t}^{F}+\tau_{t}^{F} w_{t}\right)
\end{aligned}
$$

where the superscripts $P$ and $F$ denote the PAYG and funded pillars, respectively. The total pension contribution rate is $\tau=\tau^{P}+\tau^{F}$. The pension benefits are given by

$$
b_{j, t}= \begin{cases}f_{j, t}^{P}+f_{j, t}^{F}, & \text { if } j=J \\ 0, & \text { otherwise. }\end{cases}
$$

The government collects all the pension contributions and pays out the pension benefits.

We assume that the return on pension assets exceeds the return on PAYG contributions, i.e. $r>g$. With this assumption we stack the odds against PAYG and thus raise the bar for dismantling the funded pension pillar. We will nevertheless show that maintaining the funded pension pillar is politically not feasible.

Voting Decisions are made under pure majority voting. Each period starts with or without a social security system in place. To capture the reality of a number of Central and Eastern European countries, if a such a system is in place, it consists of only a PAYG pillar or the combination of a PAYG and funded pillar. Voters can choose among three policy scenarios. First, if there is a funded pillar, they vote whether they want to retain it or to dismantle it, while capturing its assets. If they decide the latter, the pensions of the existing retired are left intact, but the assets of the working individuals go to the government's budget. The value of the assets captured from them become recorded as entitlements in the PAYG pillar. Subsequent contributions that were originally intended for the funded part are now directed to the PAYG pillar. Second, they vote whether at all to keep a pension system in place. If they decide to abandon the pension system in its entirety, any payment of pension benefits and contributions is terminated. In particular, in order to relate our results to those of Cooley and Soares (1999a), we consider the possibility to dismantle the PAYG pillar when a funded pillar is absent. We will show that the sequence of the votes does not affect our results, i.e. there are no voting cycles.

Denote the pension system with which period $t$ is entered by $\theta_{t-1} \in\{0,1,2\}$, where 0 indicates no pension system at all, 1 indicates a pension system with only a PAYG pillar, and 2 indicates a pension system with both a PAYG and a funded pillar. The results of the vote are summarized by $\theta_{t} \in\{0,1,2\}$, where, again, 0 denotes that no pension pillar is kept, 1 that only the PAYG pillar is kept, and 2 that both the PAYG and funded pillar are kept intact. The following assumption summarizes the voting outcomes and the dynamics of the pension arrangements.

Assumption 1. Define by $\mathcal{P}\left(\theta_{t-1}\right)$ the set of possible outcomes over which individuals vote. Once a pillar of the pension system is dismantled it cannot be restored, i.e. $\mathcal{P}\left(\theta_{t-1}=1\right)=\{0,1\}$ and $\mathcal{P}\left(\theta_{t-1}=0\right)=\{0\}$. Further, individuals' decisions on selecting $\theta_{t} \in \mathcal{P}\left(\theta_{t-1}\right)$ translate into the following individual pension contributions and entitlements (PAYG pillar) or assets (funded pillar) 
per individual of age $j+1$ in period $t+1$ :

$$
\begin{aligned}
& \tau_{t}^{P}\left(\theta_{t-1}, \theta_{t}\right)= \begin{cases}\tau^{P}, & \text { if } \theta_{t-1}=2 \text { and } \theta_{t}=2 \\
\tau, & \text { if } \theta_{t-1}=2 \text { and } \theta_{t}=1 \\
\tau, & \text { if } \theta_{t-1}=1 \text { and } \theta_{t}=1 \\
0, & \text { otherwise }\end{cases} \\
& \tau_{t}^{F}\left(\theta_{t-1}, \theta_{t}\right)= \begin{cases}\tau^{F}, & \text { if } \theta_{t-1}=2 \text { and } \theta_{t}=2 \\
0, & \text { if } \theta_{t-1}=2 \text { and } \theta_{t}=1 \\
0, & \text { if } \theta_{t-1}=1 \text { and } \theta_{t}=1 \\
0, & \text { otherwise }\end{cases} \\
& f_{j+1, t+1}^{P}\left(\theta_{t-1}, \theta_{t}\right)= \begin{cases}(1+g)\left(f_{j, t}^{P}+\tau_{t}^{P} w_{t}\right), & \text { if } \theta_{t-1}=2 \text { and } \theta_{t}=2 \\
(1+g)\left(f_{j, t}^{P}+f_{j, t}^{F}+\tau_{t}^{P} w_{t}\right), & \text { if } \theta_{t-1}=2 \text { and } \theta_{t}=1 \\
(1+g)\left(f_{j, t}^{P}+\tau_{t}^{P} w_{t}\right), & \text { if } \theta_{t-1}=1 \text { and } \theta_{t}=1 \\
0, & \text { otherwise }\end{cases} \\
& f_{j+1, t+1}^{F}\left(\theta_{t-1}, \theta_{t}\right)= \begin{cases}(1+r)\left(f_{j, t}^{F}+\tau_{t}^{F} w_{t}\right), & \text { if } \theta_{t-1}=2 \text { and } \theta_{t}=2 \\
0, & \text { if } \theta_{t-1}=2 \text { and } \theta_{t}=1 \\
0, & \text { if } \theta_{t-1}=1 \text { and } \theta_{t}=1 \\
0, & \text { otherwise }\end{cases}
\end{aligned}
$$

Hence, Assumption 1 describes the possible evolutions of the contributions and entitlements under the assumed majority vote. When funded pillar assets are captured, pension benefit payments in that period are unaffected. This is because the current PAYG benefit payments are paid from current contributions by the working-age population, while the funded part of the benefits is paid out of the retirees' assets accumulated up to that period. That is, in the period in which assets are captured, funded pension benefits are still given by (3), hence equal $b_{J, t}^{F}=(1+r)\left(f_{J-1, t-1}^{F}+\tau_{t-1}^{F} w_{t-1}\right)$ for $j=J$, where $b_{J, t}^{F}$ is the benefit paid by the funded pillar. The total asset capture is given by the accumulated funded pension assets of those who are not retired in period $t$ :

$$
\sum_{j=1}^{J-1}\left(f_{j, t}^{F}+\tau^{F} w_{t}\right)
$$

using that the size of each cohort is normalized to 1 . Because the indexation rate in the PAYG pillar differs from the rate of return in the funded pillar, there are differences in the retirement benefits depending on the pension system with which period $t$ is entered:

$$
\begin{array}{llll}
\theta_{t-1}=1 & \text { and } & \theta_{t}=1 & \left.: b_{J, t+1}=(1+g)\left((1+g) \tau w_{t-1}+\tau w_{t}\right)\right) \\
\theta_{t-1}=2 & \text { and } & \theta_{t}=1 & \left.: b_{J, t+1}=(1+g)\left((1+r) \tau^{F} w_{t-1}+(1+g) \tau^{P} w_{t-1}+\tau w_{t}\right)\right)
\end{array}
$$


The first equation gives the retirement benefit in period $t+1$ of someone who starts his working career when only PAYG social security is in place, while the second equation is the retirement benefit in period $t+1$ of someone who starts his working career when the funded pillar is still in place, but this funded pillar is dismantled in the second period of his working life.

The government budget The government uses lump-sum taxes to finance exogenous government purchases $G_{t}=(1+g) G_{t-1}$, which grow at the rate of growth of the economy's wage bill, and a potential subsidy $S u b s_{t}$ to the pension system. The government budget constraint reads

$$
G_{t}+S u b s_{t}+(1+r) D_{t}=\sum_{j} \Upsilon_{t}+\mathbf{1}_{\left\{\theta_{t-1}=2, \theta_{t}=1\right\}} \sum_{j=1}^{J-1}\left(f_{j, t}^{F}+\tau^{F} w_{t}\right)+D_{t+1}
$$

where $D_{t}$ denotes the outstanding public debt at the end of period $t-1$ and $\mathbf{1}_{\left\{\theta_{t-1}=2, \theta_{t}=1\right\}}$ is an indicator function, which takes on a value of 1 when the combination $\left(\theta_{t-1}=2, \theta_{t}=1\right)$ materializes and zero, otherwise. The term $\mathbf{1}_{\left\{\theta_{t-1}=2, \theta_{t}=1\right\}} \sum_{j=1}^{J-1}\left(f_{j, t}^{F}+\tau_{t}^{F} w_{t}\right)$ arises from the fact that if funded pension assets of workers are captured in period $t$, these assets as well as the pension contributions to the funded pillar are diverted to the government's budget constraint. In periods without asset capture, this term is zero. Hence, if pension assets are captured in period $t$, a government surplus emerges in that period. This is followed by a government deficit in period $t+1$, because $r>g$ and the original promise on the return on the funded pillar contributions in period $t-1$ is maintained, but the entitlement associated with this contribution is now recorded in the PAYG pillar. By contrast, all contributions in period $t$ get uprated at the growth rate of the total wage bill $g$. Hence, assuming that government debt is zero at the start of period $t$, to cover the deficit of the PAYG pillar in period $t+1$, the government needs to end with an amount of debt:

$$
D_{t+1}\left(\theta_{t-1}, \theta_{t}\right)= \begin{cases}-\frac{1}{1+r} \cdot \tau^{F} w_{t-1}\left((1+g)(1+r)-(1+g)^{2}\right), & \text { if } \theta_{t-1}=2 \text { and } \theta_{t}=1 \\ 0, & \text { otherwise }\end{cases}
$$

Hence, debt at the end of period $t$ is negative, and equals the difference between the gross return in period $t+1$ on the funded pillar contribution in period $t-1$, assuming that the contribution still earns the market return in period $t$, and the "standard" gross return in a PAYG scheme, multiplied by the amount contributed. The resulting number needs to be discounted to period $t$.

The PAYG budget constraint The budget constraint of the PAYG pillar is:

$$
b_{t}^{P}=\sum_{j=1}^{J-1} \tau_{t}^{P} w_{t}+S u b s_{t}
$$

Timing First, the state of the economy is observed. Next, individuals vote on the possible outcomes described above. Then, the lump-sum tax is determined via the government budget constraint. Finally, after observing the aggregate state $S_{t}=\left(\theta_{t-1}, \theta_{t}, D_{t}\right)$ and given their private state $s_{j, t}=\left(a_{j, t}, f_{j, t}^{F}, f_{j, t}^{P}\right)$, individuals make decisions. 
Individual decisions For a given state $\left(s_{j, t}, S_{t}\right)$, prices, and government policy functions $\theta_{t}=$ $\theta\left(\theta_{t-1}\right), G\left(S_{t}\right)$ and $\Upsilon\left(S_{t}\right)$, an individual solves:

$$
V_{j, t}\left(s_{j, t}, S_{t}\right)=\max _{\left(c_{j, t}, a_{j+1, t+1}\right)}\left\{u\left(c_{j, t}\right)+\delta V_{j+1, t+1}\left(s_{j+1, t+1}, S_{t+1}\right)\right\}
$$

subject to the budget constraint (2) and the relationships between pension contributions and benefits determined by the specific pension arrangement.

Definition 1. Equilibrium:

A Markov Perfect Equilibrium is a policy function describing voting outcomes $\theta\left(\theta_{t-1}\right)$ given state of the economy, lump-sum taxes $\Upsilon\left(S_{t}\right)$, the consumer's policy function $\left(c_{j, t}\left(s_{j, t}, S_{t}\right), a_{j, t}\left(s_{j, t}, S_{t}\right)\right)$ and value function $V_{j, t}\left(s_{j, t}, S_{t}\right)$, such that:

- $\theta_{t}=\theta\left(\theta_{t-1}\right) \in \mathcal{P}\left(\theta_{t-1}\right)$ is a policy selected in pure majority voting.

- the policy and value functions, $\left(c_{j, t}\left(s_{j, t}, S_{t}\right), a_{j, t}\left(s_{j, t}, S_{t}\right)\right)$ and $V_{j, t}\left(s_{j, t}, S_{t}\right)$ respectively, solve the individual's problem (7).

- the government budget constraint (4) holds.

\subsection{Results}

We present three main theoretical results. First, we show that (under weak conditions) the political stability of the PAYG pillar found by Cooley and Soares (1999a) carries over to the current setting, i.e. $\theta_{t}=\theta\left(\theta_{t-1}=1\right)=1$. Once a PAYG pillar is introduced, no future vote to abandon it succeeds. Second, we show that the funded pillar is not stable, i.e. $\theta_{t}=\theta\left(\theta_{t-1}=2\right) \neq 2$. Third, we show that in equilibrum a situation with both a funded and a PAYG pillar will evolve such that the PAYG pillar is maintained, while the assets of the funded pillar are captured and the contributions are shifted, i.e. $\theta_{t}=\theta\left(\theta_{t-1}=2\right)=1$. For brevity, we drop the time indices when a variable is dated to period $t{ }^{6}$

Proposition 1. Assume that the economy starts with a PAYG pension pillar only, i.e. $\theta_{t-1}=1$. If $r<1+2 g$, the system is politically stable in the sense that voters will always vote to keep it, i.e. $\theta_{t}=\theta\left(\theta_{t-1}=1\right)=1$.

Proof. See online Appendix A.

The intuition for this result is analogous to that in Cooley and Soares (1999a), although they derive the result in general equilibrium setting, while here it is derived in a partial equilibrium setting. It is based on the commonality of the interests between the retired and the middle-aged individuals. Given the structure of the economy and because preferences are strictly monotonic, it suffices to show how different policies affect the budget constraint of individuals. Pensioners would lose if the PAYG system is dismantled, because they have already paid their contributions during their working life and cannot recover them, while they would lose their retirement benefit. Middle-aged individuals face the a trade-off between dismantling the PAYG pillar and losing the contributions made so far and benefitting from a higher return $r>g$ on putting new contributions into a savings account instead.

\footnotetext{
${ }^{6}$ For example, $w$ will be short-hand notation for $w_{t}$.
} 
Unless the interest rate is extremely high, the former dominates. Young individuals prefer to abandon the pension system, but they are outnumbered by the retired and the middle-aged.

Second, we show that for a funded pillar, the analogue of Cooley and Soares (1999a) does not hold. In fact, there is now a commonality of interests of the young and the old to capture the funded pillar assets.

Proposition 2. Assume that the economy starts with both a PAYG pillar and a funded pillar, i.e. $\theta_{t-1}=2$. Then voters vote to dismantle the funded pillar, i.e. $\theta_{t}=\theta\left(\theta_{t-1}=2\right) \neq 2$.

Proof. See online Appendix A.

Hence, the funded pillar is politically unsustainable. The intuition is that old individuals have their pension unaffected, but benefit from reduced taxation financed by the asset capture. Because $r>g$, young individuals see their pension reduced by the asset capture. However, the lower taxes more than compensate for this decline. The asset capture shifts the burden of financing the pensions of the current young to future cohorts, who lose but are not represented in the vote.

We now show what is an equilibrium. Starting from a two-pillar scheme, assets are captured by a coalition of the young and the old with contributions being redirected to the PAYG pillar, while the PAYG pillar is sustained by a coalition of the middle-aged and the old.

Proposition 3. The PAYG pension pillar, and only the PAYG pension pillar, is politically sustainable, i.e. $\theta_{t}=\theta\left(\theta_{t-1}\right)=1$ for $\theta_{t-1} \in\{1,2\}$, so long as $r<1+2 g$.

Proof. See online Appendix A.

We can show that the sequence in which the alternatives are voted upon does not affect the final outcome, which is a Condorcet winner of pure majority voting. We can also show that the above propositions hold in the presence of elastic labor supply and labor taxation.

Concluding their investigation, Cooley and Soares (1999a) argue that the political stability of a PAYG pillar crucially depends on the general equilibrium effects implied by the presence of social security, in particular their influence on the capital stock formation and the return to private capital. Hence, they conjecture that political stability cannot simply be assessed by a partial equilibrium comparison of $r$ and $g$. To address this issue, the remainder of this paper studies the political stability of funded pension pillars in a quantitative general equilibrium small-open economy framework. In addition, other stylized setups in the literature emphasize the role of potential coalitions between heterogeneous agents (including Cooley and Soares 1999b). The idea is that political outcomes may be affected by a preference for redistribution from high to low productivity individuals. Therefore, our quantitative setup also features ex-ante intra-cohort heterogeneity.

\section{A quantitative model}

This section constructs a fully-fledged small-open economy model that allows for realistic calibration and evaluation of the political sustainability of pension arrangements. It features a large number of overlapping generations and intra-cohort heterogeneity in a variety of relevant dimensions. Cohorts are no longer of equal size over time, but shrink over time due to individuals dying with some probability 
that increases with age. The initial steady state is calibrated to replicate the Polish economy and features a PAYG-DB pension system, i.e. pensions are a fixed fraction of wage earnings. Then, a reform to a two-pillar DC system is introduced, which keeps the total contribution rate unchanged and honors the obligations towards the older generations. This partial privatization of social security improves welfare in a Kaldor-Hicks sense and has political support in a pure majority vote at the moment of implementation when pension assets are still zero. To analyze the political sustainability of the funded pillar, we allow for a subsequent vote on capturing the assets accumulated in the funded pillar. As suggested by the existing literature, the cohorts benefitting from pension funding would eventually gain a majority, which would guarantee the long-term political viability of the two-pillar scheme. However, the currently alive - even if they benefit from higher pensions under a funded pillar - may still prefer to capture the accumulated assets: the welfare gain from contemporaneously lower taxes may outweigh the welfare loss due to lower pension benefits. As future cohorts cannot vote, the consequences for these cohorts do not affect the outcome of the vote.

Our model features intra-cohort heterogeneity to capture two important aspects relating to such heterogeneity. First, the earlier literature on pension system reform suggests that in voting for redistribution coalitions form across cohorts and productivity types, in the spirit of Aaron (1966) and Cooley and Soares (1999a). To assess the role of intra-generational heterogeneity, we also report results for when such heterogeneity is absent. Second, poverty, both in old-age and when young and on low income, is a political concern. Allowing for intra-cohort heterogeneity enables us to study the dynamics of poverty and compare the policy outcomes along this metric.

\subsection{International capital markets}

Households have access to international capital markets in which they can borrow or lend at the interest rate $r_{t}$. As proposed by Schmitt-Grohe and Uribe (2003), the domestic interest rate $r_{t}$ equals the world interest rate $r_{t}^{*}$, adjusted for a risk premium according to:

$$
r_{t}=r_{t}^{*}+\xi \frac{D_{t}^{*}}{Y_{t}}
$$

where $D_{t}^{*}$ is the level of foreign debt of the economy, $Y_{t}$ denotes GDP and $\xi$ is a constant. Hence, an increase in the ratio of foreign debt to GDP raises the interest rate at which domestic individuals can borrow in international markets. ${ }^{7}$

\subsection{Households}

Each individual of type $\kappa \in 1, \ldots, \mathcal{K}$ lives for up to $J$ periods, with age denoted as $j \in\{1,2, \ldots, J\} .{ }^{8}$ Individuals of the same age are heterogeneous with respect to productivity and the utility function parameters. The size of subcohort $\kappa$ of age $j$ in period $t$ is $N_{j, \kappa, t}$. The discount factor of an individual

\footnotetext{
${ }^{7}$ Not allowing for the risk premium would result into implausibly large swings in the net foreign asset position. Since we calibrate the model to the case of Poland, an emerging economy, if we were to make the assumption that the economy is closed, the (endogenous) interest rate would over time fall due to the convergence of the productivity level to that of advanced economies. However, Poland, being part of the EU internal market, is better characterized as an open economy. Our main findings go through under the closed-economy assumption. The detailed results are available upon request.

${ }^{8}$ In our simulations $j=1$ corresponds to 21 years of age and $j=J$ to 100 years of age, as mortality tables usually go up to 100 years. Hence, we set $J=80$.
} 
of type $\kappa$ is $\delta_{\kappa}$. Individuals face a non-zero probability of dying in each period. The unconditional probability that an individual of age $j$ is still alive at time $t$ is denoted by $\pi_{j, t}$. This probability is homogeneous within the cohort. Rising longevity is obtained through rising survival probabilities over time.

Individuals choose consumption $c_{j, \kappa, t}$, labor $l_{j, \kappa, t}$, for which they receive a real wage $w_{t}$ per efficiency unit, and assets $a_{j, \kappa, t}$, which earn a rate of return $r_{t}$, to maximize the following Bellman equation:

$$
V_{j, \kappa, t}\left(a_{j, \kappa, t}\right)=\max _{c_{j, \kappa, t}, l_{j, \kappa, t}}\left\{u_{\kappa}\left(c_{j, \kappa, t}, l_{j, \kappa, t}\right)+\delta_{\kappa} \frac{\pi_{j+1, t+1}}{\pi_{j, t}} V_{j+1, \kappa, t+1}\left(a_{j+1, \kappa, t+1}\right)\right\}
$$

where $\pi_{j, t}$ is the probability of being alive at age $j$ in period $t$ and $u_{\kappa}\left(c_{j, \kappa, t}, l_{j, \kappa, t}\right)=\ln c_{j, \kappa, t}+\phi_{\kappa} \ln (1-$ $\left.l_{j, \kappa, t}\right)$, with $\phi_{\kappa} \geq 0, \forall \kappa$. Individuals face the following budget constraint

$$
\left(1-\tau_{c}\right) c_{j, \kappa, t}+a_{j+1, \kappa, t+1}+\Upsilon_{t}=\left(1-\tau_{l}\right) \Psi_{j, \kappa, t}+\left(1+r_{t}\left(1-\tau_{k}\right)\right) a_{j, \kappa, t}+\mathcal{B}_{j, \kappa, t},
$$

where $\tau_{c}$ is the consumption tax rate, $\tau_{l}$ denotes the labor income tax rate, $\tau_{\kappa}$ the capital income tax rate, $\Upsilon_{t}$ lump-sum taxes and $\mathcal{B}_{j, \kappa, t}$ assets unintentionally bequeathed. Bequests of voluntarily accumulated assets are evenly distributed amoung the remaining members of subcohort $\kappa$ of age $j$. Further, $\Psi_{j, \kappa, t}$ is current-period gross income from labor or pension, which is given by:

$$
\Psi_{j, \kappa, t}= \begin{cases}(1-\tau) w_{t} \omega_{\kappa} l_{j, \kappa, t}, & \text { for } j<\bar{J} \\ b_{j, \kappa, t} & \text { for } j \geq \bar{J}\end{cases}
$$

Here, $\tau$ denotes the social security contribution rate, $\bar{J}$ the retirement age, $\omega_{\kappa}$ productivity of an individual in subcohort $\kappa$ and $b_{j, \kappa, t}$ the pension benefit, which we discuss below.

\subsection{Firms}

We assume a perfectly-competitive production sector that uses labor $L_{t}$ and capital $K_{t}$ to produce output $Y_{t}$ with the Cobb-Douglas technology:

$$
Y_{t}=K_{t}^{\alpha}\left(z_{t} L_{t}\right)^{1-\alpha}
$$

where $L_{t}$ is aggregate effective labor input and $z_{t}$ captures exogenous labor-augmenting technological progress. Hence, profit is maximized when the net return on capital $r_{t}-d$, where $d$ denotes the depreciation rate of capital, equals the marginal product of capital and the real wage rate $w_{t}$ equals the marginal product of labor:

$$
\begin{aligned}
r_{t} & =\alpha K_{t}^{\alpha-1}\left(z_{t} L_{t}\right)^{1-\alpha}-d \\
w_{t} & =(1-\alpha) K_{t}^{\alpha} z_{t}^{1-\alpha} L_{t}^{-\alpha}
\end{aligned}
$$




\subsection{Pension arrangements}

The benefits paid from the PAYG-DB pension arrangement in the initial steady state are given by:

$$
b_{j, \kappa, t}^{P A Y G-D B}= \begin{cases}0, & \text { for } j<\bar{J} \\ \rho \omega_{\kappa} w_{t-1} l_{j-1, \kappa, t-1}, & \text { for } j=\bar{J} \\ \left(1+g_{t}\right) b_{j-1, \kappa, t-1}^{P A Y G B-D B} & \text { for } \bar{J}<j \leq J\end{cases}
$$

Hence, the benefits in the first year of retirement are expressed in terms of the replacement rate $\rho$ of the last pre-retirement earnings. In this system, the contributions of the currently working are used to pay the pensions of the currently retired, while a potential deficit needs to be plugged with a

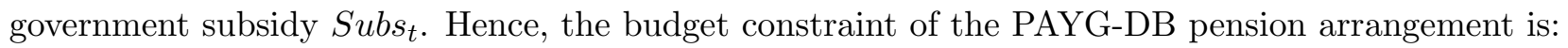

$$
\sum_{\kappa=1}^{\mathcal{K}} \sum_{j=\bar{J}}^{J} N_{j, \kappa, t} b_{j, \kappa, t}^{P A Y G-D B}=\tau w_{t} L_{t}+S u b s_{t} .
$$

When the economy starts it is assumed to be in its initial steady state with the PAYG-DB pension system just described. After one year, the system is unexpectedly reformed into a partially-funded DC system with a PAYG and a funded pillar. The respective individual contribution rates are $\tau^{P}$ and $\tau^{F}$, while the total contribution rate is kept equal to the original contribution rate $\tau$ under the PAYG-DB scheme, i.e. $\tau^{P}+\tau^{F}=\tau .{ }^{9}$ We denote by $b^{P}$ and $b^{F}$ the benefits paid from the respective pillars.

The emergence of this two-pillar DC scheme can be rationalized as the outcome of a vote in which individuals weigh a number of factors. ${ }^{10}$ First, with a PAYG-DB system increasing longevity would require a permanent subsidy from the government, because a longer life at retirement would raise the amount of pensions to be paid out. The resulting deficit would need to be financed with higher consumption taxes and debt according to the fiscal rule given by equation (21) below. Replacement by a DC scheme would eventually render the pension system balanced, which reduces taxes in the long run. Second, progressing longevity would imply PAYG-DB pensions eventually exceeding DC pensions, ceteris paribus. Third, with the interest rate on assets exceeding the growth rate of the wage bill, funded pensions would exceed those paid by the PAYG pillar. Fourth, during the transition period to the two-pillar DC scheme, a deficit would emerge in the pension system, necessitating a transitory increase in taxes, which would be smoothed by a transitory increase in the public debt. Finally, there would be general equilibrium effects, stemming from an adjustment in private voluntary savings and in the labor supply, because the tighter link between contributions and benefits in the DC system would strengthen work incentives.

\footnotetext{
${ }^{9}$ Such a reform was introduced in Poland in 1999 and in a number of other Central and Eastern European countries, as well as Sweden, over the course of the 1990s and 2000s (see Holzman and Stiglitz 2001, Orszag and Stiglitz 2001, Jarrett 2011, Schwarz 2011, Schwartz 2014).

${ }^{10}$ In practice, after a reform, PAYG-DB pensions are usually maintained for cohorts close to retirement at the moment of the reform. For example, in Poland cohorts older than 40 years at the moment of the change continued to receive pensions according to the pre-reform rules. Hence, for the vote to introduce the two-pillar DC scheme we assume that cohorts older than 40 years at the moment of the vote continue to receive pensions according to equation (14), while all younger cohorts receive pensions according to equations (17) and (18) below.
} 
The entitlements to the new PAYG-DC pillar grow at the rate of growth of the total wage bill $g_{t} .{ }^{11}$ Contributions to the funded pillar are invested against a return $r_{t}$. Hence, during their working life, the individuals' accounts in both pillars evolve as:

$$
\begin{aligned}
f_{j+1, \kappa, t+1}^{P} & =\frac{\pi_{j+1, t+1}}{\pi_{j, t}}\left(1+g_{t}\right)\left(f_{j, \kappa, t}^{P}+\tau_{t}^{P} \omega_{\kappa} w_{t} l_{j, \kappa, t}\right) \\
f_{j+1, \kappa, t+1}^{F} & =\frac{\pi_{j+1, t+1}}{\pi_{j, t}}\left(1+r_{t}\right)\left(f_{j, \kappa, t}^{F}+\tau_{t}^{F} \omega_{\kappa} w_{t} l_{j, \kappa, t}\right) .
\end{aligned}
$$

At retirement, each account is converted into an annuity. However, the difference in indexation rates between the two pillars remains. ${ }^{12}$ Summarizing, the pension benefits are given by:

$$
\begin{aligned}
& b_{j, \kappa, t}^{P}= \begin{cases}0, & \text { for } j<\bar{J} \\
f_{\bar{J}, \kappa, t}^{P} / L E_{\bar{J}, t}, & \text { for } j=\bar{J} \\
\left(1+g_{t}\right) b_{j-1, \kappa, t-1}^{P} & \text { for } \bar{J}<j \leq J\end{cases} \\
& b_{j, \kappa, t}^{F}= \begin{cases}0, & \text { for } j<\bar{J} \\
f_{\bar{J}, \kappa, t}^{F} / L E_{\bar{J}, t}, & \text { for } j=\bar{J} \\
\left(1+r_{t}\right) b_{j-1, \kappa, t-1}^{F} & \text { for } \bar{J}<j \leq J\end{cases}
\end{aligned}
$$

with $L E_{\bar{J}, t}=\sum_{s=0}^{J-\bar{J}} \frac{\pi_{\bar{J}+s, t+s}}{\pi_{\bar{J}, t}}$ denoting life expectancy at retirement.

During the transition period, the non-funded pillar pays out DB pension benefits $b^{P A Y G-D B}$ to those not affected by the reform and DC pension benefits $b^{P}$, while the part of the contributions $\tau^{F}$ originally used to finance PAYG-DB benefits goes into the funded pillar. ${ }^{13}$ Hence, there is a transitory deterioration in the balance of the non-funded pillar, because from the total contribution rate $\tau$ the non-funded pillar receives only $\tau^{P}=\tau-\tau^{F}$. The deterioration is eliminated with a subsidy, conform equation (15). Once the transition is complete, $S u b s_{t}$ is again zero.

The transition from a PAYG-DB system to a two-pillar DC system, as described above, constitutes the baseline scenario of our simulations. The analyzed voting scenarios will comprise further changes to the two-pillar DC system setup. We allow agents to vote in favor of dismantling the funded part of the two-pillar system at different dates. In the simulations individuals evaluate their potential gains and losses from capturing the assets accumulated in the funded pillar. However, they do not vote strategically in that (i) they care only about their own welfare and (ii) they do not expect the vote to repeated in the future. This is an approach similar to Phelan (2006).

\subsection{The government}

The government collects revenues to finance exogenous government purchases $G_{t}$, the deficit in the non-funded part of the pension system and the servicing of the public debt $D_{t}$. These revenues are:

\footnotetext{
${ }^{11}$ The relevant formula is given by $g_{t}=w_{t} L_{t} /\left(w_{t-1} L_{t-1}\right)-1$.

${ }^{12}$ Contributions of those agents who die prior to claiming benefits are added to the accounts of the survivors, i.e. they are distributed equally within each birth cohort and, hence, remain within the pension system.

${ }^{13}$ For details on the pension system reform in Poland, see Chlon et al. (1999).
} 


$$
T_{t}=\tau_{l}\left[(1-\tau) w_{t} L_{t}+\sum_{\kappa=1}^{\mathcal{K}} \sum_{j=\bar{J}}^{J} b_{j, \kappa, t}^{\bullet} N_{j, \kappa, t}\right]+\sum_{\kappa=1}^{\mathcal{K}} \sum_{j=1}^{J}\left(\tau_{c, t} c_{j, \kappa, t}+r_{t} \tau_{k, t} a_{j, \kappa, t}\right) N_{j, \kappa, t},
$$

where $b_{j, \kappa, t}^{\bullet}$ denotes relevant pension benefits. The first term on the right-hand side is the sum of the taxation of labour income, after social security contributions have been paid, plus the taxation of retirement benefits, while the second term is the sum of the taxation of consumption and capital income. The government budget constraint is:

$$
G_{t}+S u b s_{t}+r_{t} D_{t}=T_{t}+\left(D_{t+1}-D_{t}\right)+\sum_{\kappa=1}^{\mathcal{K}} \sum_{j=1}^{J} N_{j, \kappa, t} \Upsilon_{t}
$$

The final term is lump-sum taxes aggregated over all groups. Whenever a budget deficit emerges, it is absorbed by an adjustment in public debt. However, if debt exceeds its steady-state value, this also triggers an adjustment of the consumption tax rate:

$$
\tau_{c, t}=(1-\varrho) \tau_{c}^{\text {final }}+\varrho \tau_{c, t-1}+\varrho_{D}\left((D / Y)_{t}-(D / Y)^{f i n a l}\right),
$$

where $\varrho$ captures the smoothing of the consumption tax rate and $\varrho_{D}$ the strength of the reaction to a deviation of the government debt ratio of GDP from its steady-state value. Here, $\tau_{c}^{f i n a l}$ and $(D / Y)^{\text {final }}$ denote the new steady-state values of the consumption tax rate and the debt-to-GDP ratio, respectively. Our fiscal rule is forward-looking in the sense that $(D \tilde{/ Y})_{t}$ is a moving average of the debt ratio over the past two, the current and the next two years. This allows consumption taxes to react to debt in the near future.

\subsection{Closing the model}

The model is closed with market clearing conditions for:

$$
\begin{array}{ll}
\text { the labor market: } & L_{t}=\sum_{\kappa=1}^{\mathcal{K}} \sum_{j=1}^{\bar{J}-1} N_{j, \kappa, t} \omega_{\kappa} l_{j, \kappa, t}, \\
\text { the capital market: } & K_{t}+D_{t}=\sum_{\kappa=1}^{\mathcal{K}} \sum_{j=1}^{J} N_{j, \kappa, t}\left(a_{j, \kappa, t}+f_{j, \kappa, t}^{F}\right)+B_{t}, \\
\text { the goods market: } & \sum_{\kappa=1}^{\mathcal{K}} \sum_{j=1}^{J} N_{j, \kappa, t} c_{j, \kappa, t}+G_{t}+K_{t+1}+N X_{t}=Y_{t}+(1-d) K_{t},
\end{array}
$$

where $N X_{t}$ denotes the current account. The net foreign debt evolves over time according to:

$$
D_{t+1}^{*}-D_{t}^{*}=r_{t} D_{t}^{*}-N X_{t} .
$$

\subsection{The political process}

We assume that the collective decision concerning the future of the pension system is made through pure majority voting. Individuals who would benefit from the policy change favor the alternative over the status quo. The welfare effect of a policy change for a type $\kappa$ individual of age $j$ in year $t$ is 
expressed in terms of the fractional increase in consumption over the remaining lifetime resulting from the change:

$$
W_{j, \kappa, t}=1-\exp \left(\frac{V_{j, \kappa, t}^{b}-V_{j, \kappa, t}^{r}}{\sum_{s=0}^{J} \delta_{\kappa}^{s} \frac{\pi_{j+s, t+s}}{\pi_{j, t}}}\right),
$$

where $t$ is the voting date, $V_{j, \kappa, t}^{b}$ the utility under the status-quo scenario and $V_{j, \kappa, t}^{r}$ the utility under the alternative policy. We refer to this as the "certainty-equivalent consumption change".

The vote: capturing assets from the funded pillar The status quo for the vote we study now is the pension arrangement with a PAYG DC pillar and a funded DC pillar that came unexpectedly into existence one year after the start of the game. We assume that also the new vote comes unexpectedly. To determine the outcome of the vote starting from the status quo with a PAYG and a funded DC pillar, we calculate the net individual welfare effects of capturing the assets accumulated in the funded pillar. Concretely, individuals vote between between maintaining the current two-pillar DC pension system and a combination of reducing the funded pillar and increasing the PAYG-DC pillar. Once there is sufficient political support for reducing the funded pillar, individuals treat this outcome as permanent in evaluating their welfare, i.e. they expect no further vote.

We compare the results of votes at different dates in the future. The reason for this is that the state of the economy is changing over time. First, assets in the funded pillar take time to accumulate. Second, and more fundamentally, the literature on "privatizing social security" suggests that, because reforms benefit future cohorts, once the original transition from the PAYG-DB to the two-pillar DC system is completed, the latter system should have become politically stable. However, as we will see, this turns out not to be the case, because reducing the funded pillar offers immediate gains at the expense of future cohorts.

We allow individuals to vote on different possible ways to reduce the funded pillar. First, they can decide about diverting (part of) the social security contributions away from the funded pillar to the PAYG pillar, while keeping the existing stock of assets in the funded pillar untouched. This option does not reduce the overall contribution rate, but it shifts the balance between the two pension pillars. ${ }^{14}$ We refer to this change as Policy 1. Policy 1 mimics the type of changes that have been temporarily or permanently implemented by all Central and Eastern European countries in the aftermath of the global financial crisis. Because in most countries following such policy part of the contributions continued to be transferred to the funded pillar, we assume that a successful vote to alter the current arrangement changes the proportions in the allocation of the contributions to the two pension pillars. More specifically, we assume that prior to the vote $\tau^{P}=2 \tau^{F}$, whereas after a successful vote the proportions change to $\tilde{\tau}^{P}=9 \tilde{\tau}^{F}$, while maintaining the total contribution rate, i.e. $\tau^{P}+\tau^{F}=$ $\tilde{\tau}^{P}+\tilde{\tau}^{F}=\tau .{ }^{15}$ This shift will be permanent, resulting into a permanent reduction of the funded pillar relative to the PAYG pillar.

Second, while keeping the contributions to the two pillars unchanged, voters can decide that the assets in the funded pillar are transferred to the PAYG pillar. Since the government balances the

\footnotetext{
${ }^{14}$ Hence, the predictions of studies such as Browning (1975), Butler (2000) do not apply to our case (see also Congleton et al. 2013, for an additional treatment).

${ }^{15}$ The considered proportions prior to and after the vote replicate the Polish case, but the analysis can easily be extended to any proportion of policy relevance.
} 
pension system, it takes the form of large transfer from pension system to the government budget constraint (a negative subsidy). We call this policy "asset capture" and in the remainder of the paper we denote this by Policy 2. Such changes have been implemented by Hungary, Bulgaria, Poland and Slovakia, although to a varying extent. In Hungary the nationalization of the accumulated assets was immediate and complete, whereas in the other countries it was partial and gradual. This policy change does not directly reduce the size of the pension system in the economy. ${ }^{16}$ This policy is transitory in the sense that, while the accumulated assets are captured, new asset accumulation in the funded pillar resumes as of the next period.

Third, in some countries Policies 1 and 2 were implemented simultaneously. Thus, we allow for a Policy 3, which combines Policies 1 and 2, hence merges both a shift in contributions and asset capture in the same vote, thereby combining permanent with transitory effects.

Each of these policies has different effects on the welfare of the current and future cohorts. Policy 1 reduces the current deficit in the PAYG scheme at the expense of slower capital accumulation and lower pension benefits. With general government consumption fixed, a reduction in $S u b s_{t}$ allows for a reduction in taxes relative to the status quo scenario during the original transition period. However, once the transition from the two-pillar DC system to the new system is complete, taxes have returned to their original level. Meanwhile, since the return in the PAYG pillar is lower than in the funded pillar, Policy 1 results in permanently lower future pension benefits compared to the status quo for this vote. Policy 2 reduces immediately the debt of the government. This allows current and future taxes to be reduced, because also subsequent costs of servicing the public debt fall. With the fiscal rule described in equation (21), taxes do not adjust immediately, but the eventual reduction in consumption taxes can nonetheless be large. Clearly, these changes are accompanied by lower individual pension benefits.

Only those alive at the moment of the vote can cast their vote. An individual is in favor of a policy change if her subsequent lifetime utility is higher than under the status quo. Overall, voters are given four options: (1) stick with the status quo; (2) select Policy 1; (3) select Policy 2; and (4) select Policy 3. Each of the Policies $1-3$ is pitched against the status quo in a majority vote. The sequence in which these votes take place does not affect the eventual outcome. ${ }^{17}$

\section{Calibration}

We calibrate the model to match the features of the Polish economy as an example of a country that replaced its PAYG-DB system with a two-pillar DC system and continued with essentially unchanged features of the new system for over a decade, after which it effectively dismantled the funded pillar. To avoid biases in the calibration due to business cycle fluctuations, we rely on averages over the decade prior to the reform, which started in 1999. We use the detailed demographic projection released by the Ageing Working Group (AWG) of the European Commission to reproduce the arrival of new cohorts to the economy, as well as the annual survival probabilities of each subsequent birth cohort. The projection is available until 2080. We assume that mortality and birth rates are constant after 2080. Consequently, the population declines at a rate of $1 \%$ per year in the final steady state.

\footnotetext{
${ }^{16}$ There is an indirect effect, because of the lower return on the PAYG than on the funded pillar, resulting into lower accumulated pension obligations. See Casamatta et al. (e.g. 2001) for a treatment of this case.

${ }^{17}$ See Dhami and al Nowaihi (2010) for a proof of the transitivity.
} 
We also use the projection for the exogenous technological progress from the AWG as of 2010, whereas for the years between 1999 and 2010 we use the moving-average (to smooth out cyclical fluctuations) growth rate of total factor productivity (TFP) obtained from the data for this period. The AWG scenario for productivity assumes a gradual convergence to the annual average EU TFP growth rate of $1.54 \%$ between 2010 and 2040, after which it remains constant at this rate.

The retirement age $\bar{J}$ is calibrated to the data on the effective retirement age collected by the OECD. It equals 61 in 1999 and remains constant throughout the projection. ${ }^{18}$ These assumptions are used in all the scenarios. The replacement rate in the initial PAYG-DB system is set so as to replicate the share of pensions in GDP prior to the reform of 1999. Knowing the replacement rates, we set the overall contribution rate $\tau$ to replicate the pension system deficit of $0.8 \%$ of GDP observed in the years before the reform. The split between $\tau^{P A Y G}$ and $\tau^{F}$ after the switch to the two-pillar DC scheme follows the proportions set by the Polish legislation.

Table 1: Calibrated parameters for the initial steady state

\begin{tabular}{|c|c|c|c|c|}
\hline \multicolumn{2}{|r|}{ Macroeconomic parameter } & \multirow{3}{*}{$\begin{array}{c}\text { Calibration } \\
0.5 \\
0.992\end{array}$} & \multirow{2}{*}{$\begin{array}{c}\text { Target } \\
\text { average hours }\end{array}$} & \multirow{2}{*}{$\frac{\text { Actual value (source) }}{56 \%(\mathrm{LFS})}$} \\
\hline$\overline{\phi \phi}$ & preference for leisure & & & \\
\hline$\delta$ & discount rate & & interest rate & $6 \%$ \\
\hline$\tau_{l}$ & labor tax rate & 0.084 & revenue as \% of GDP & $9.2 \%(\mathrm{OECD})$ \\
\hline$\tau_{c}$ & consumption tax rate & 0.220 & revenue as $\%$ of GDP & $3.8 \%(\mathrm{OECD})$ \\
\hline$\tau_{k}$ & capital income tax rate & 0.190 & de iure & \\
\hline$\rho$ & replacement rate & 0.228 & benefits as $\%$ of GDP & $5.0 \%(\mathrm{SIF})$ \\
\hline$\tau$ & social security contr. rate & 0.06 & SIF deficit as $\%$ of GDP & $0.8 \%(\mathrm{SIF})$ \\
\hline$\alpha$ & capital share & 0.300 & & \\
\hline$d$ & depreciation rate & 0.035 & investment rate & $21 \%(\mathrm{NA})$ \\
\hline$r^{*}$ & world interest rate & $3 \%$ & & \\
\hline$\xi$ & sensitivity of $r$ to $B / Y$ & 0.030 & domestic inv. as $\%$ of GDP & $16 \%(\mathrm{NA})$ \\
\hline & Fiscal rule parameters & & & \\
\hline$\rho$ & tax rate persistence & 0.800 & & \\
\hline$\rho_{D}$ & strength of debt-tax link & 0.300 & & \\
\hline$D / Y$ & government debt-to-GDP ratio & 0.450 & & $45 \%$ (NA) \\
\hline
\end{tabular}

Notes: Tax shares in GDP obtained from the OECD Tax Revenue database. "LFS" stands for the Polish Labor Force Survey and has been averaged over the 1995-2010 period, "SIF" stands for the annual reports of the Social Insurance Fund (in Polish: Fundusz Ubezpieczen Spolecznych), and "NA" stands for the National Accounts.

We use the data on the employment rate from the Labor Force Survey to calibrate the aggregate preference for leisure $\phi$. Subsequently, we seek the discount factor $\delta$ and the capital depreciation rate $d$ that would be consistent with the national savings rate of approximately $16 \%$ of GDP and the investment rate of approximately 21\% of GDP, as observed on average between 1990 and 1999 . We calibrate the global interest rate to 3\%. Following Schmitt-Grohe and Uribe (2003) we set the coefficient $\xi$ governing the debt-elastic interest-rate premium at 0.03 . While this number may be on the high side, if anything, by raising the return on domestic investment it biases the setting against our main result that a funded pillar is not politically sustainable.

Based on the standard figure used in the literature, we assume that the elasticity of output with

\footnotetext{
${ }^{18}$ The eligible retirement age was 55 for women and 60 for men. In 2009 the government terminated early retirement for the majority of the work force, although some occupations remained entitled to early retirement. In 2012, the government imposed a gradual increase of the eligible age to 67 for both genders, but in 2015, before this legislation had effectively come into force, the increase was already reversed, resulting into a current eligible age of 60 for women and 65 for men, with an entitlement to claim partial benefits from the ages of 58, respectively 63 .
} 
respect to capital is $\alpha=30 \%$. The share of government expenditure of GDP is set at 20\%, to replicate the actual proportion. The capital income tax rate $\tau_{k}$ is set at de iure rate of $19 \%$. The labor income tax rate $\tau_{l}$ is calibrated to replicate the ratio between labor income tax revenue and labor income in the national accounts, thus at its effective rather than its nominal rate. We calibrate the value of the consumption tax rate $\tau_{c}$ to match the value-added tax revenues as a share of GDP. We also assume that the initial and final government debt-to-GDP ratio equals $45 \%$, which corresponds to actual debt ratio in the late 1990s in Poland. By calibrating the final debt-to-GDP ratio at the initial one, we eliminate the effects associated with a change in the long-run debt ratio. To assure a smooth evolution of the consumption tax rate, we set $\rho=0.9$ and $\rho_{D}=0.065$. Finally, we calibrate the necessary lump-sum tax revenues to match the deficit-to-GDP ratio. The parameter values are summarized in Table 1.

\subsection{Calibrating the intra-cohort heterogeneity}

There are three dimensions of intra-cohort heterogeneity: the preference for leisure, the time preference and individual productivity. ${ }^{19}$ We calibrate this heterogeneity using individual level data. ${ }^{20}$

Individual productivity $\omega_{\kappa}$ We use linked employer-employee data to reduce biases, such as those associated with self-reporting, inherent in labor force surveys. Therefore, we use the Structure of Earnings Survey, designed by Eurostat and collected biennially by the national statistical offices. ${ }^{21}$ This survey covers roughly 700,000 employees, for which all individual characteristics such as age, gender, earnings, sector and occupation, as well as actual hours worked, are reported by the employer. Since in our model individual labor productivity is determined once for the entire lifetime, we use the early (first five) career years to obtain the distribution of these productivities. We estimate a standard Mincerian wage regression with education levels, occupation, industry and region controls, as well as the form of contract (fixed term or permanent) and the form of employment (part-time, full-time, weekends, etc.). We use total hourly wages, including overtime and bonuses. We take the logarithm of the fitted value of the hourly wage and obtain the final distribution of individual productivities depicted in Figure B.2 in Appendix B, which we discretize to the set of values $\omega_{\kappa} \in$ $\{0.70,0.76,0.84,0.93,0.98,1.03,1.08,1.14,1.20,1.26\}$ relative to a mean of $1 .^{22}$

Leisure preference parameter $\phi_{\kappa}$ Individual preferences for leisure versus consumption determine labor supply decisions, so we calibrate these to replicate the employment ratio in the decade prior to 1999. Individual preferences for leisure are heterogeneous, with a fraction of the population working part-time or not at all. We rely on reported hours actually worked in the Structure of Earnings Survey which range from $31 \%$ to $206 \%$ of the regular working time. This yields the set of values for the leisure preference parameter $\phi_{\kappa} \in\{0.0 \phi, 0.5 \phi, 1.0 \phi, 1.5 \phi\}$, where $\phi$ is the economy-wide leisure

\footnotetext{
${ }^{19}$ The three dimensions of heterogeneity are assumed to be independent. Our setup allows for any potential correlation between the different types of heterogeneity. However, empirical research identifying such correlations is scarce.

${ }^{20}$ (Hénin and Weitzenblum 2005, McGrattan and Prescott 2013, Kindermann and Krueger 2014, For a discussion on the estimates for household rather than individual data, see, for example, )

${ }^{21}$ We use data from the 1998 wave to calibrate the distribution of individual productivities.

${ }^{22}$ Whether we express the distribution relative to the mean $(\log )$ wage or its median value is quantitatively irrelevant for the distribution of $\kappa$. The results for individual productivity relative to the median are available upon request.
} 
preference parameter reported in Table 1 . The distribution scaled by the amount of mean hours worked is depicted in Figure B.2 in Appendix B.

The discount factor $\delta_{\kappa}$ The economy-wide discount factor $\delta$ is calibrated to replicate the interest rate, given the depreciation rate. As far as we are aware, there is no empirical literature to guide us in calibrating the heterogeneity in the discount factor across agents. We assume symmetric departures from the economy-wide discount factor and calibrate the spread around the latter such that the wealth inequality in 1999 is replicated by our model. Davies et al. (2011) and a household wealth survey by the National Bank of Poland ${ }^{23}$ yield a range for the Gini coefficient of wealth between 65.7 in 2000 and 57.9 in 2014 . We target the mid-point of these two values, assuming that $40 \%$ of the individuals have the average discount factor, while $30 \%$ of the individuals have a lower- or higher-than-average discount factor. Concretely, $\delta_{\kappa} \in\langle 0.988 \delta, 1.0 \delta, 1.012 \delta\rangle$, where $\delta$ is the economy-wide discount factor reported in Table 1. This calibration yields a Gini coefficient of wealth of 62 in the initial steady state.

\subsection{Solving the model}

We solve the individual's problem analytically. In order to reduce the dimensionality of the problem we use the "implicit tax approach" proposed by Butler (2002), i.e. we split the pension system contributions into an implicit savings rate, which by construction is age-specific, and an implicit tax rate. In a DB system, a contributing individual perceives no link between its own labor supply and its future pension benefit, hence its entire contribution is perceived as a tax. In the DC system, the link is embedded in the actuarial formulas given by equations (16)-(18).

Once the individual's problem is solved by each $\kappa$-type of agent at each age $j$, for a given set of prices and taxes, we apply the Gauss-Seidel algorithm to obtain the general equilibrium. Using the outcomes of the individuals' problems, the aggregate variables are updated. The procedure is repeated until the difference between the path of aggregate capital from subsequent iterations has become negligible. ${ }^{24}$ We set the length of the transition path in order to assure that the new steady state is reached, i.e. the last generation in the simulation lives its entire life in the new steady state.

\section{$5 \quad$ Results}

The major forces behind establishing the funded pillar and later capturing the assets from this pillar have already been laid out. Introducing a funded pillar causes a transitory budgetary gap, but increases the pension benefits. The transitory budgetary gap can be smoothed across generations via adjustments in taxes and public debt, thus making such reform politically more acceptable. The previous literature emphasized typically the short-run costs and long-term gains. Capturing assets accumulated in the funded pillar embodies the opposite: the generation which captures the assets benefits from lower taxes in the short run, but experiences a cost in terms of lower pension benefits

\footnotetext{
${ }^{23}$ This is a standardized tool developed within the Household Finance and Consumption Network of the European System of the Central Banks.

${ }^{24}$ Specifically, this is the case if the $L_{1}$-norm of the difference between the subsequent iterations of the vector describing the time path of the capital stock falls below $10^{-12}$.
} 
only later. If the captured assets are in addition used to reduce the public debt, the lower debt-servicing costs benefit individuals also in the foreseeable future.

This reasoning is further refined by recognizing that voters may have heterogeneous preferences. In general, all individuals prefer living in an economy with high levels of capital (as long as the economy remains dynamically efficient). For example, future generations benefit from current capital accumulation because the marginal productivity of labor increases with the capital stock. However, the benefits from further capital accumulation differ by age at the moment of voting. Older individuals - retired or close to retirement - care more about the return on capital than about wage growth, because their consumption depends more on income from holding capital. Capturing assets lowers the capital-to-labor ratio as a result of a fall in the capital stock and an increase in the labor supply among the younger generations who need to save more for their old age. Hence, the return on capital increases. At the same time, the pension benefits of the elderly will not be hurt much. Even if these effects are transitory, they raise the support for asset capturing among the older cohorts. Meanwhile, younger individuals, who still expect to work for many years at the time of vote, are mostly interested in the wage growth. Hence, they prefer to maintain a sufficiently large capital stock. Naturally, the loss associated with a decline in capital can be partially or fully offset by a decline in taxes. Overall, older agents will typically be in support of capturing assets, while younger agents will ceteris paribus be more in favor if the reduced-tax channel dominates the reduced-wage channel.

In Appendix $\mathrm{C}$ we demonstrate that the unexpected introduction of a two-pillar DC system after one period into the game, the status quo of the vote considered below, has sufficient political support at the moment of implementation. The two-pillar DC system improves welfare in a Kaldor-Hicks sense: compared to the PAYG-DB system, the two-pillar DC system features a certainty-equivalent permanent consumption rise of $1.2 \%$. The support comes mostly from the older cohorts, owing to the fact that introducing a DC system raises the incentives for labor supply (see Figure C.5). Hence, the economy-wide wage bill grows faster, allowing to raise the indexation rate on the PAYG part of the pension system. Younger cohorts enjoy this benefit too, but are negatively affected by the fact that consumption taxes have to be raised for some time since directing some of the contributions to the funded pillar necessitates fiscal adjustment in order to pay for the elderly's pensions. Moreover, the shift from PAYG-DB to two-pillar DC system has a negative effect on pensions, because the switch results in a balanced pensions system and the original PAYG-DB system was in the deficit at the date of the reform which would grow even larger with longevity. The deficit is reduced by lowering pension benefits which only partially is made up for by the fact that funded pillar pays higher pensions due to the fact that $r>g$.

We also show that as the oldest cohorts pass away, the shae of the population benefiting from a two-pillar DC system declines gradually (see Figure C.4 in Appendix C) and only starts to increase again when the cohorts working at the time of the reform have passed away. The two-pillar DC system again reaches a majority of net beneficiaries only as late as in 2060 , i.e. once a sufficient share of newborn cohorts populates the economy (see Figure C.5 in Appendix C). Finally, we show that around 2100, i.e., one hundred years after the two-pillar system is introduced, it benefits all subcohorts at the start of their life after their specific type has materialized. Hence, one would expect that by then the two-pillar DC system should have become politically stable. We show below that this is not 
the case.

\subsection{Capturing assets accumulated in the funded pillar}

In Table 2 we report the results for simulations with a vote on a potential capture of pension assets in 2012. We repeat the vote every 30 years until 2192. In that year, the economy has completed the transition, i.e., it has reached a stationary equilibrium (a final steady state with stationary, but declining population). Hence, voting in subsequent periods would yield the same results. The distribution of welfare across the birth cohorts is reported in Figure 2 for voting in 2012 and in Figure 3 for voting in 2192. In all the cases studied here, expected utility at birth, both before and after the allocation to the subcohort is known, in the long-run stationary equilibrium is reduced by capturing assets from the funded pillar. The static comparison between the two-pillar DC scheme and the alternative policies exhibits an ex-ante certainty-equivalent lifetime consumption loss of $-0.59 \%$ for Policies 1 and 3, while Policy 2 has no long-term welfare effect, because it involves a one-off appropriation.

Table 2: Political support for the three alternatives to the two-pillar DC status quo

\begin{tabular}{|c|c|c|c|c|c|c|c|}
\hline Year of voting & 2012 & 2042 & 2072 & 2102 & 2132 & 2162 & 2192 \\
\hline Political support in \% of those alive & \multicolumn{7}{|c|}{ Against status quo with two pillars } \\
\hline for Policy 1 - shifting contributions (permanent) & 99 & 99 & 99 & 99 & 99 & 99 & 99 \\
\hline for Policy 2 - capturing assets (one-off) & 52 & 62 & 64 & 61 & 61 & 62 & 62 \\
\hline for Policy 3 - combination of Policies 1 and 2 & 99 & 90 & 94 & 94 & 90 & 94 & 94 \\
\hline Political support in $\%$ of those alive & \multicolumn{7}{|c|}{ Against the winning policy (i.e. Policy 3 ) } \\
\hline Policy 1 - shifting contributions (permanent) & 48 & 35 & 36 & 40 & 39 & 38 & 38 \\
\hline Policy 2 - capturing assets (one-off) & 1 & 1 & 2 & 1 & 0 & 0 & 0 \\
\hline
\end{tabular}

Notes: Under Policy 1 the share of contributions going to the funded pillar is reduced, while the overall contribution rate stays the same. Under Policy 2 assets accumulated in the funded pillar are captured. Policy 3 combines Policies 1 and 2, i.e. it amounts to a permanent reduction of the contributions to the funded pillar and a one-off appropriation of pension assets.

Even though the winning policy reduces welfare in the long-run, at the moment of the vote it improves the situation of a sufficient fraction of living agents at the expense of future generations to warrant political support from a majority of the voters. For them, the gains from lower consumption taxes dominate the losses from lower pension benefits. Future generations, by contrast, cannot enjoy lower taxes, while the pension system delivers permanently lower retirement benefits and higher taxation of private assets. Thus, for those cohorts the losses dominate the gains from an ex-ante perspective. This result also partly arises because individuals have access to a savings technology and use their perfect foresight to smooth consumption via private voluntary savings. From an individual's perspective, this is a suboptimal way of consumption smoothing - both in our framework and in reality - because the contributions to the funded pillar are exempt from capital income taxation, whereas private voluntary savings are not. Yet, the effects associated with declining debt and taxes dominate the loss in terms of higher capital income taxes.

To understand the sources of the political support, we first look at the relative roles of fiscal adjustments and pension adjustments. Both adjustments are reported in Figure 1. Relative to the status quo, pensions decline only moderately, whereas the adjustment in taxes is sizable. While the 
cost of the asset capture is determined by the cumulative return difference on pension wealth resulting from the difference between $r$ and $g$, the gain is determined by the entire accumulated pension wealth.

Figure 1: The effect of a succesful vote against the two-pillar DC status quo on pensions and taxes

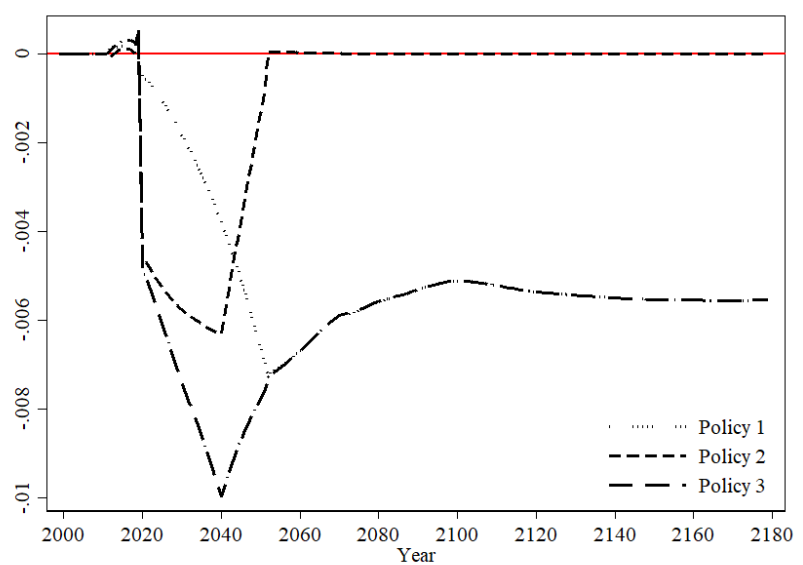

(a) average pensions (change from baseline in \%)

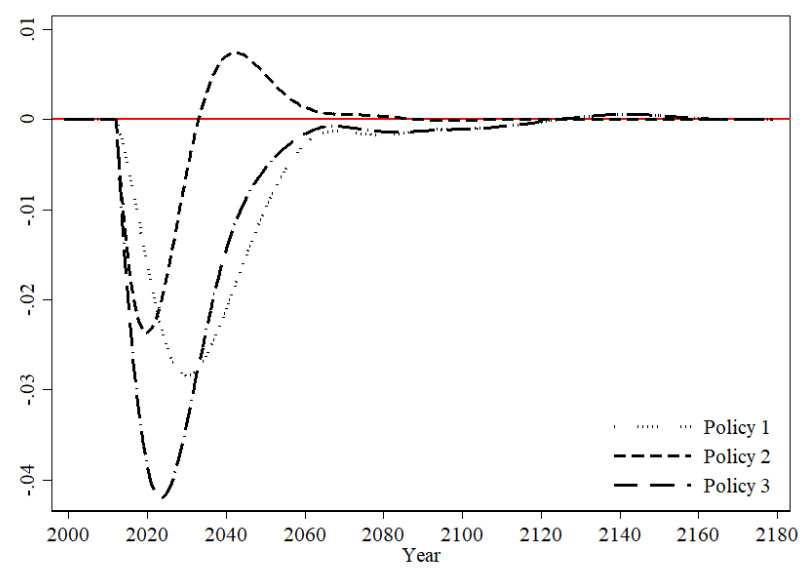

(b) consumption taxes (change from baseline in percentage points)

Note: Results from the voting round in 2012 (results for the other rounds are available upon request). Average pensions expressed as fractional deviation from baseline level. For example, -0.01 is equivalent to $1 \%$ lower pensions. Consumption taxes are expressed as percentage point deviation from the status quo level. For example, -0.04 is equivalent to a tax rate that is 4 percentage points lower. Policy 1 is a permanent shift of the contributions from the capital pillar to the PAYG pillar. Policy 2 is a one-off capturing of the assets accumulated in the funded pillar. Policy 3 combines Policies 1 and 2. The levels of pensions and taxes as well as debt adjustments are reported in Figure D.7 in Appendix D.

For the voting round of 2012, Figure 2 decomposes by cohort the overall welfare effect into effects from changes in taxes and pensions, and a general equilibrium effect. The decomposition is done as follows. For example, to calculate the "tax component", we use the consumption taxes under the given policy and take all other macroeconomic aggregates from the status quo. Based on these prices and quantities we calculate the welfare effect of the new policy. For the cohorts born after the vote, Policy 1 leads to a welfare loss, resulting from lower pensions dominating the beneficial tax and general equilibrium effects. Despite the negative pension effects, older cohorts benefit on net because of these effects. However, Policy 1 improves the welfare of almost all living cohorts, and almost solely by the tax channel. Policy 2 leads to a more varied pattern in which the youngest and future born are worse off, while it benefits retirees and individuals who were not affected by the initial 1999 reform and have little or no assets in the funded pillar. Reduced taxation is essentially the only source of the net gains. Net losers are also the cohorts with the largest funded pillar assets and who are close to retirement, i.e. who were younger than 40 in 1999. The pattern for Policy 3 is rather similar to that for Policy 1.

Looking at the voting round of 2192 (see Figure 3), in which the economy is close to the steady state resulting from the original switch from PAYG-DB to the two-pillar DC system, we observe that the pattern of cohorts on net benefiting and on net losing is rather similar to that for the 2012 vote. Also, the contributions from tax, pension and general equilibrium effects are qualitatively rather similar. Compared to the vote in 2012, the debt increase resulting from the initial introduction of the funded pillar has almost vanished. Hence, currently-working cohorts have less debt to finance and, hence, they accumulate more financial assets, also in the DC funded pillar. As a result, the appropriation 
is more harmful in terms of a loss of future pension benefits. As a consequence, the political support for Policy 3 declines, but the policy is still favored by a majority of the voters (see Table 2), as the benefits from the tax reduction in particular still dominate the cost in terms of lower pensions.

While the birth year is the main driver behind the benefit from a change in policy, we also explore the welfare effects of the different policies for the subcohorts, i.e. for individuals after the individualspecific heterogeneity has materialized. This may be relevant, because at the moment of the vote each voter knows in which subcohort she is located. However, we find that heterogeneity at the subcohort level plays only a limited role for the voting preferences. Policy 1 is preferred by the far majority of those alive at the moment of the vote, irrespective of one's subcohort for a given birth year. There is some heterogeneity in preferences among the subcohorts for the youngest cohorts at the moment of the vote. Policy 2 is almost uniformly rejected across subcohorts by the youngest cohorts, while for Policy 3 we observe some heterogeneity by subcohort among the youngest cohorts, though not among the other cohorts. In particular, the subcohorts among the young with a high rate of time preference benefit from Policy 3, because the short-term benefit in terms of lower taxes outweighs the future cost in terms of lower pensions.

We can further portray the role of the intra-cohort heterogeneity. The left-hand panel of Figure 4 depicts the contribution of each dimension of intra-cohort heterogeneity to the variation in the consumption equivalents across subcohorts. We use ANOVA to decompose the variance in equivalent consumption variation. Of the dimensions of the intra-cohort heterogeneity, patience is quantitatively by far the most relevant one. Indeed, the most important trade-off is between the gains from lower current taxes and future efficiency losses and lower pensions. The latter obviously receive a lower weight when the rate of time preference increases. Since the fiscal channel is dominant in determining welfare effects, individuals experience roughly the same welfare effects regardless of the intensity of their preference for leisure and their individual productivity. The right-hand panel compares the overall intra-cohort and inter-cohort welfare dispersions. Clearly, the year of birth is substantially more relevant for the welfare effects of the policies voted upon than is the heterogeneity within each birth cohort.

The results from the vote in different years are reported in Table 2. Ultimately, the funded pillar never becomes politically stable. Indeed, in spite of its potential attractiveness from an ex-ante perspective, individuals always massively vote in favor of reducing the funded pillar. The permanent shift of contributions from the funded to the PAYG pillar, Policy 1, is favored regardless of the year of the vote. Moreover, individuals are in favor of permanent rather than one-off policy variants: Policy 2 is also always preferred to the status quo of the original two-pillar DC system, but the combination of Policy 1 and Policy 2 has systematically even higher political support, i.e., Policy 3 is always favored. The benefit from reduced taxation during the voters' remaining lifetime is reinforced by the fact that, prior to the vote, savings have been stimulated by the higher marginal productivity of labor, hence higher wage rate, due to the extra capital accumulated via the funded pillar. This larger amount of savings benefits from the increase in the interest rate when assets are captured. This effect is of particular relevance for the retired cohorts. The costs associated with a reduction of the funded pillar are mainly born in the future and get relatively little weight in today's trade off, because of discounting. Appendix D presents a detailed analysis of the effects on the macroeconomy and pensions 
Figure 2: Welfare effects and its decomposition of a vote in 2012 by birth year.

(a) Policy 1: shifting contributions (permanent)

(b) Policy 2: capturing assets (one-off)
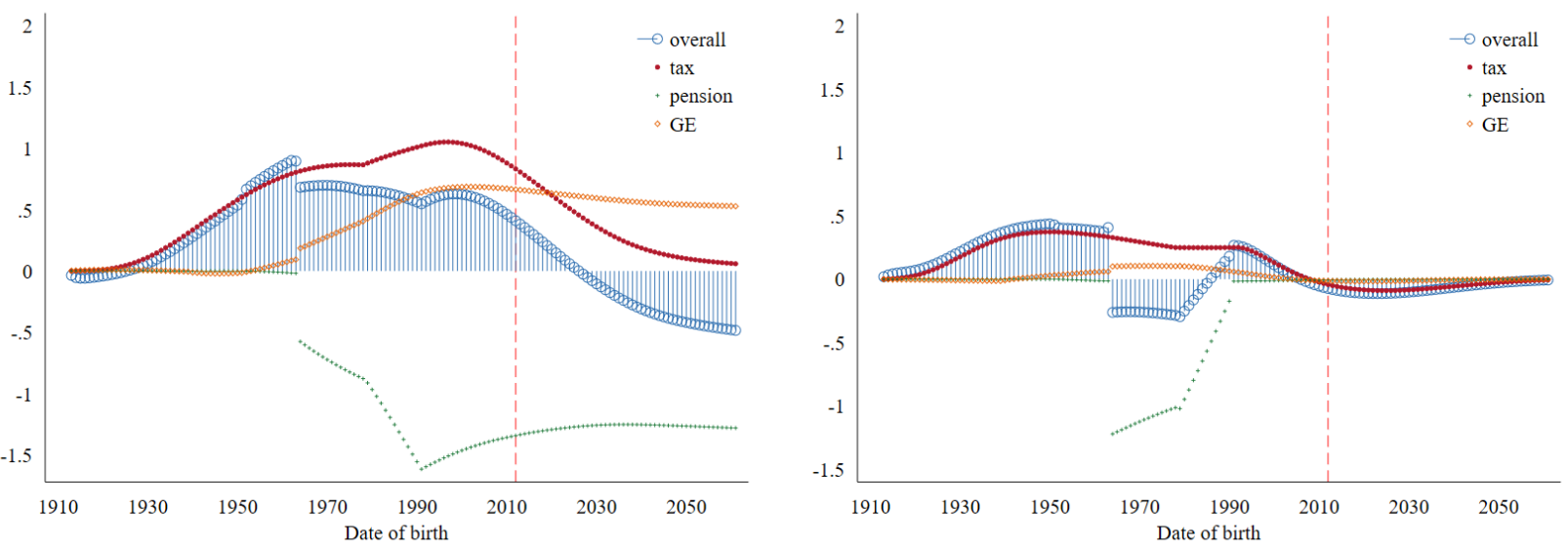

(c) Policy 3: combination of Policy 1 and Policy 2

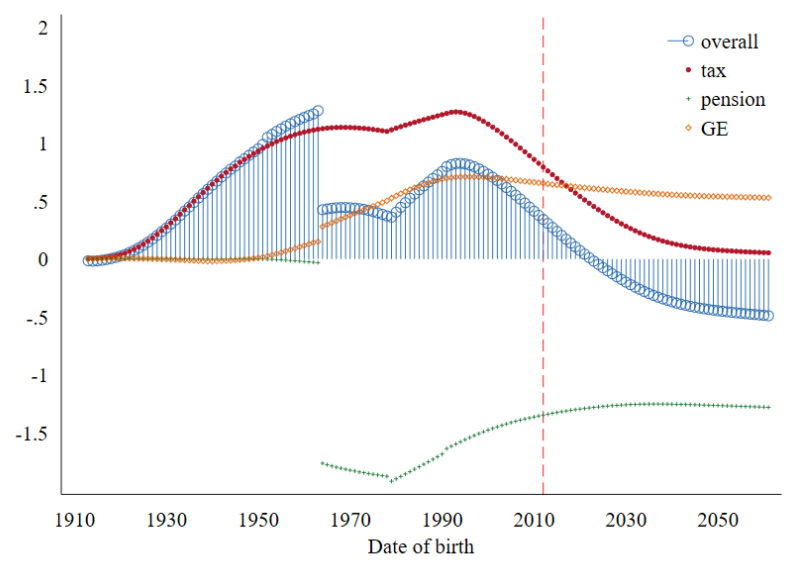

Note: The panels display the welfare effects under the new policy expressed in percent of lifetime certaintyequivalent consumption. The full set of results for each subcohort is available upon request. The decomposition above relates to a simulation under a veil of ignorance. We decompose the overall welfare effect into the components attributable to tax changes, benefit changes and general equilibrium effects. To calculate the "tax component", we use the consumption taxes under the given policy and take all other macroeconomic aggregates from the status quo. Based on these prices and quantities we calculate the welfare effect of the new policy. Similarly, to obtain the "pensions component", we use the pension benefits under the given policy and all other macroeconomic aggregates from the status quo to calculate the welfare effect. To obtain the general equilibrium component, we use the interest rate and wages under the given policy and all other macroeconomic aggregates from the status quo. Notice that due to the curvature of the utility function, it is not possible to obtain the overall welfare effect by adding up the welfare effects from these three components. 
Figure 3: Welfare effects and its decomposition of a vote in 2192 by birth year.

(a) Policy 1: shifting contributions (permanent)

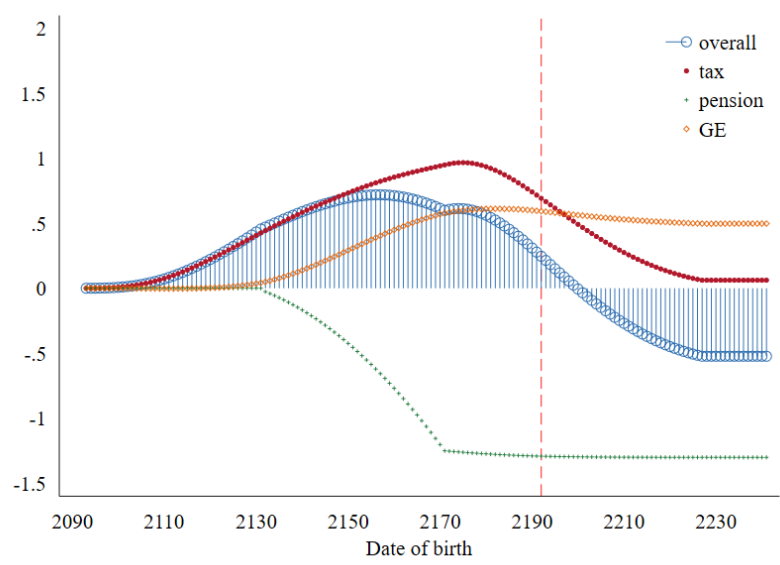

(b) Policy 2: capturing assets (one-off)

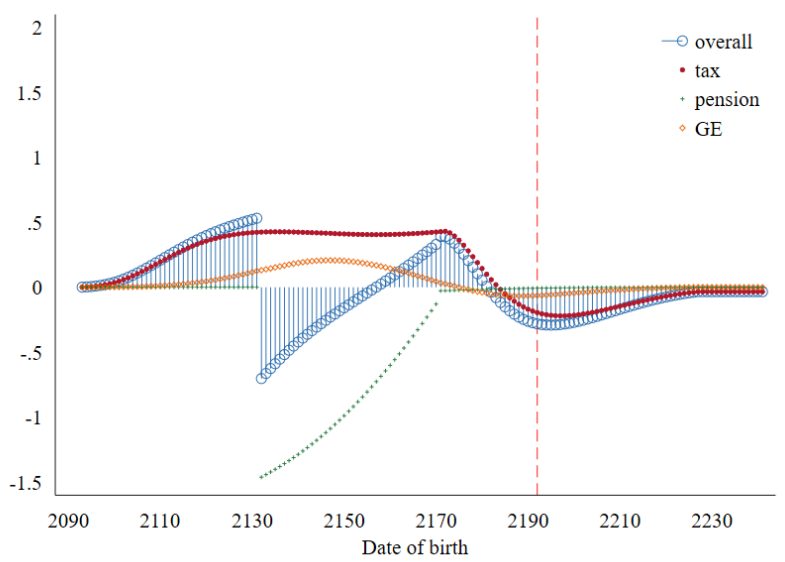

(c) Policy 3: combination of Policy 1 and Policy 2

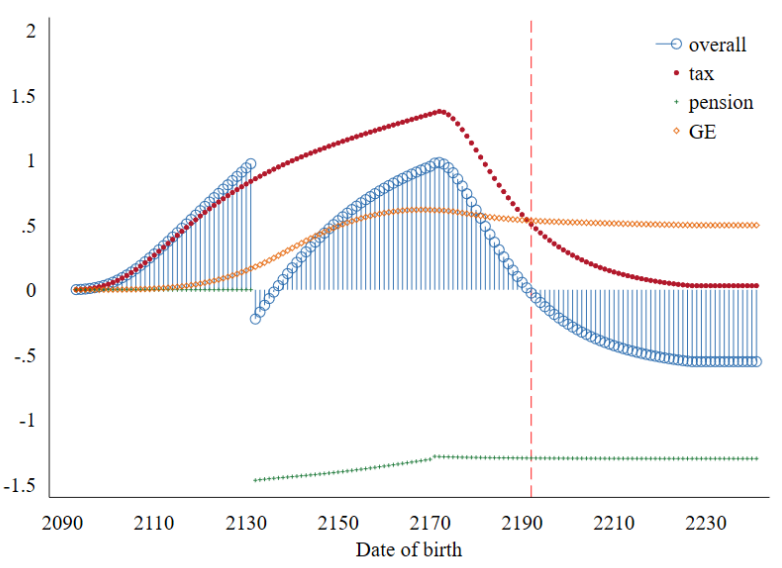

Notes: see Figure 2.

of reducing the funded pillar with a vote in 2012 .

\subsection{Robustness and extensions}

We demonstrate the robustness of our findings to some of the assumptions of the model. First, we analyze whether the demographic path is relevant and find that, even with a growing population, introducing a funded pillar gets sufficient political support, but so does the capturing of the accumulated assets afterwards. Second, we explore whether the results are sensitive to the share of asset capture that is used to reduce taxes (as opposed to reducing public debt) and we find that even if the largest part of the assets captured is used to reduce the public debt, political support for the three policies remains, because the lower debt translates into lower taxes at some moment in an individual's life. Third, we analyze the role of the rate of technological progress. Again, our results remain unaffected.

To keep the analysis tractable we also introduced some simplifications. First, voting is costless in our setup, hence essentially all individual preferences matter for the final outcomes. Recent literature pays increasing attention to the cost of voting and how it affects participation (e.g. Borgers 2004, Ghosal and Lockwood 2009, Chakravarty et al. 2018). This would be particularly relevant when it 
Figure 4: Contribution of intra-cohort heterogeneity to the dispersion of the welfare effects
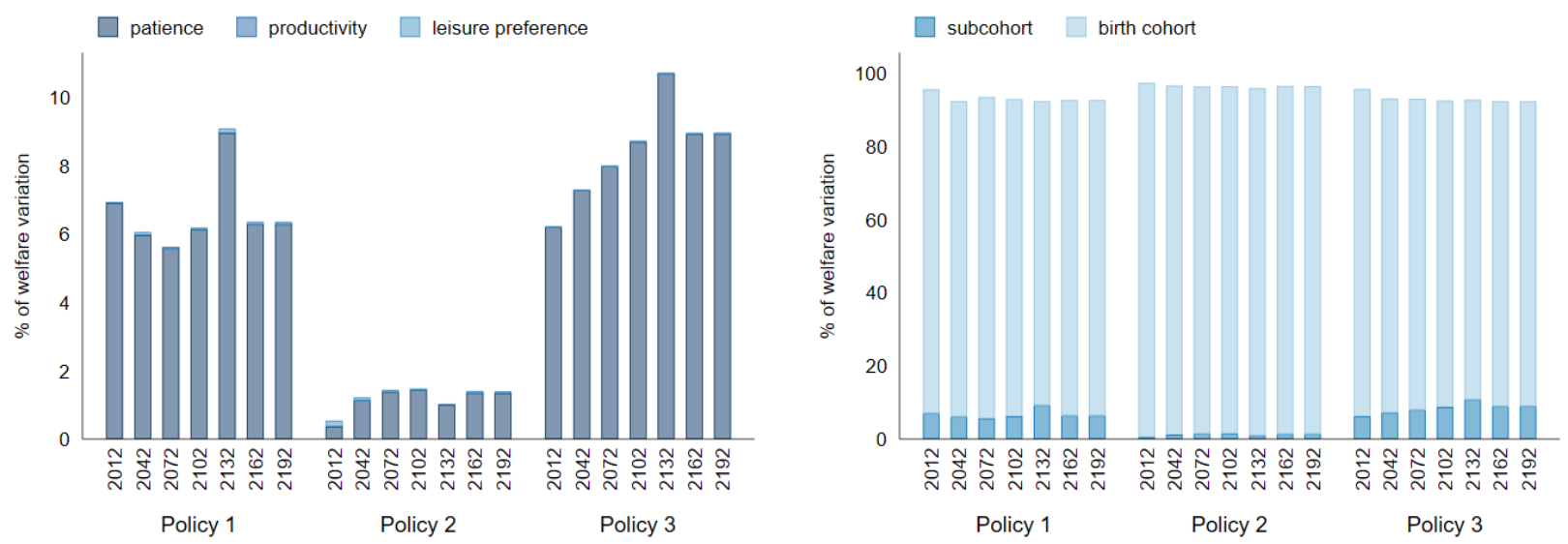

Notes: the decomposition of the variation in welfare is obtained through ANOVA, with the sample restricted to cohorts born up to 60 years before the vote and the latest born 60 years after the vote. We decompose the variation in birth cohort welfare (measured in terms of lifetime consumption equivalent) into the variation related to patience (the $\delta$ multipliers), leisure preference (the $\phi$ multipliers) and productivity (the $\omega$ multipliers). The results for votes in other years are available upon request.

affects participation unevenly across age groups or other dimensions, such as relative productivity.

Second, individuals in our model are not altruistic, i.e. when voting they are not concerned about the welfare of the future cohorts (e.g. Fisman et al. 2017). Here we also explore the case in which voters are to some extent altruistic. Concretely, individuals cast their vote on the basis of an altruistic utility function that is the sum of its own utility over consumption and leisure, as used so far, plus (with some weight) the utility over consumption and leisure of their children. Figure 5 depicts how the political support for Policies $1-3$ depends on the degree of altruism. It shows that, if agents attach a weight relative to their own utility of slightly over a half or more to their children's utility, reducing the funded pillar is no longer politically viable. ${ }^{25}$

Third, our model abstracts from social assistance to the working poor and minimum pension benefit guarantees. With such social safety nets, it is likely that the social security system would become permanently unbalanced. Increasing the share of the public pillar in the total pension system would likely raise the amount of imbalance that would have to be financed with taxes, because there would be fewer benefits from the funded pillar to alleviate poverty. In reality, these additional safety nets exist and, hence, fewer voters (especially the well off) than in our current setup might benefit from the tax cuts associated with the dismantling of the funded pillar.

In fact, the intra-cohort heterogeneity permits us to analyze also the effects on poverty, which we do in Appendix E. As Figure E.10 in Appendix E shows, the initial reform after a year since the start of the economy, which replaces the existing DB pensions with lower DC pensions, raises poverty. This is because the pensions of many individuals decline, while voluntary private savings are insufficient to maintain consumption above the poverty line. We propose two measures of poverty. The first measure is akin to an absolute poverty measure and is obtained from the baseline scenario of no policy change: we set the threshold at two thirds of median consumption in (stationary) model units, which we apply

\footnotetext{
${ }^{25}$ Here, individuals decide after they have drawn their own productivity and preferences, but before the productivity and preferences of their children have realized. Hence, they vote under a veil of ignorance about their children. The results are the same if we assume that the children inherit their parents' productivity and preferences.
} 
Figure 5: Support for reducing the funded pillar as a function of altruism: voting in 2012 (left) and 2212 (right)
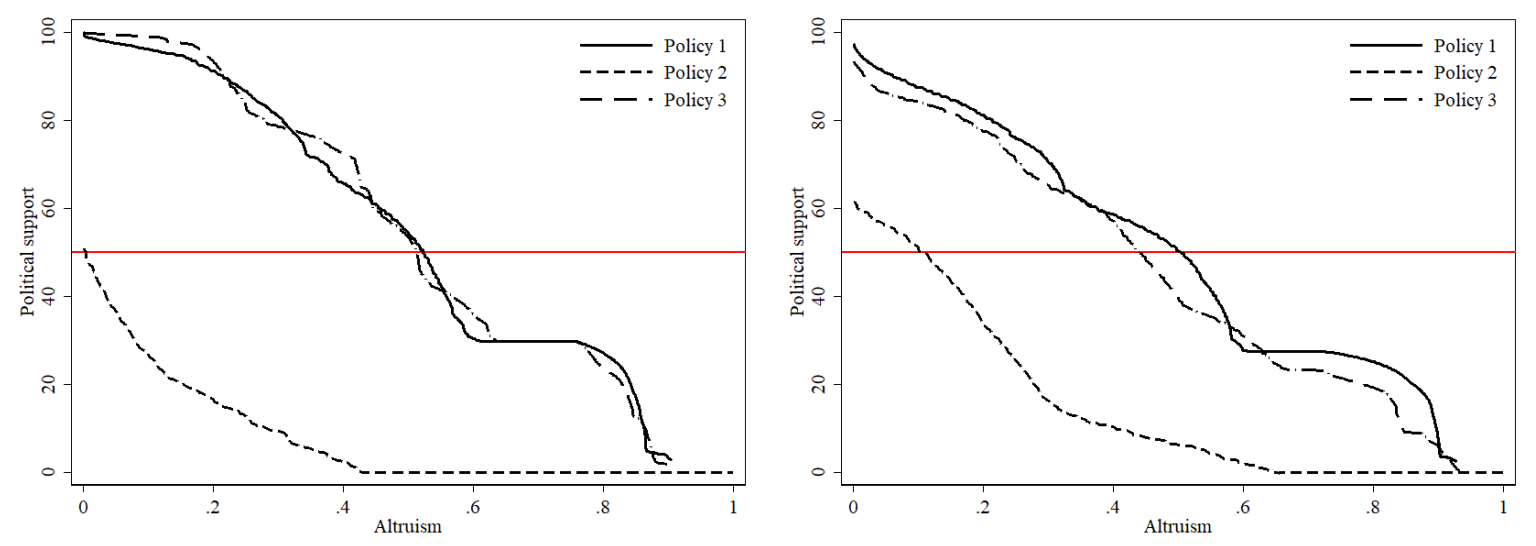

Notes: Individuals base their vote on the altruistic utility function $U_{\kappa, t}^{a}=U_{\kappa, t}+\mathcal{A} U_{t+19}$, which takes into account the "narrow" utility over consumption and leisure of both the individual and its children. Here, parameter $\mathcal{A}$ measures the degree of altruism and $\mathcal{A} U_{t+19}$ is the utility of the children over consumption and leisure as defined earlier and before their specific subcohort type is determined. If $\mathcal{A}=0$, we are back at the original analysis. The red line corresponds to $50 \%$ of the voting population.

as the poverty threshold in reform scenarios. The second measure is relative, i.e., in each scenario we compute the poverty threshold as two thirds of the median consumption in this particular scenario. We find that asset capture raises absolute poverty. Because consumption declines overall in the asset capture scenarios, the relative poverty threshold falls as well and, as a result, there is no increase in relative poverty. A detailed discussion of the mechanism behind the changes in the poverty measures is found in Appendix E.

\section{Conclusions}

The political sustainability of social security in the literature rests on the idea that a cohort that refuses to finance the pensions of their elderly is penalized with the loss of their own pension benefits. However, while this mechanism is plausible for PAYG pension systems, this is not the case for funded systems. The conventional wisdom is that the introduction of pension funding will eventually raise welfare of all the future cohorts (in a Kaldor-Hicks sense), but the cohorts alive when the funding is first introduced suffer a welfare loss: the working cohorts need to finance the pension benefits of the elderly, while at the same time they have to accumulate assets for their own retirement. The gains from introducing the funded pillar are related to the direct effects of faster capital accumulation and the indirect general equilibrium effects through changes in wages and capital returns. Consequently, introducing funding is typically portrayed as producing immediate costs and delayed gains. The literature suggests that as time passes, the fraction of living agents benefitting from the reform increases. Hence, there will come a moment when a (partially) funded pension system has become politically sustainable. In this paper, we show that this intuition is not correct.

This paper contributes to the literature by exploring whether pension system reforms are politically sustainable. We show that, even if pension funding has sufficient political support at the moment of its introduction, it may be politically unsustainable. The policy relevance of our study is immediate. 
Since introducing pension funding implies an unequal distribution of the costs and benefits across cohorts it is crucial for such a reform to be politically sustainable. Otherwise, the reform may be reversed even before society starts enjoying its benefits, implying a massive inefficiency, because costs are incurred without experiencing any gains. As is clear from the recent reversals of pension funding, such risks are not merely theoretical, but have already materialized in a number of countries. Hence, if the introduction of funding is expected to be reversed eventually, then there is no point in incurring the initial cost of the reform.

For our analysis we develop an OLG model of an economy undergoing a shift from PAYG-DB to DC with partial funding. Because in the model the obligations associated with the pension benefits of the cohorts in or close-to retirement are honored, the reform generates costs to other cohorts currently alive. Allowing public debt to partially smooth these costs generates majority support for the transition. As time passes, the reform becomes beneficial to all cohorts at the moment of their birth: it allows for faster accumulation of capital and, thanks to the funded pillar, a rise in total pension benefits relative to PAYG DB. On selected dates we allow agents to vote over shifting the contributions and/or appropriation of the assets accumulated in the funded pillar towards the PAYG-DC pillar, while keeping the total contribution rate constant. However, as we shift the date of the vote further into the future, the two-pillar arrangement never becomes politically sustainable, even once the transition from the original reform has been completed: the currently alive always benefit from capturing the assets in the funded pillar and shifting the cost of the appropriation to the future cohorts. This finding also holds if we introduce heterogeneity among individuals in terms of productivity, preferences and discounting.

One might have the impression that the share of contributions going to the funded pillar has simply been set at a too high level, so rational agents adjust it downwards to their preferred, lower level, in the spirit of Browning (1975) or Cooley and Soares (1999b). However, we demonstrate a new source of political support of dismantling funded pensions: such support is not driven by better aligning mandatory pension savings with individual savings preferences, but rather by shifting welfare from future to current cohorts. The transitory tax are the driving force in this regard.

In a broader context, our findings should be interpreted as supporting the view that the protection of property rights is key in maintaining a multi-pillar state-run pension system. Indeed, long-run credibility issues need to be addressed explicitly and ex ante, because the risk of dismantling a funded pension pillar is permanent. If pensions and/or contributions may be shifted away from the funded pillar in the future, there is a risk that introducing funding will only generate welfare costs, because there will not be enough time for the welfare gains to materialize. In some advanced economies, funded pension pillars are part of a tripartite agreement between employers, employees and the government. Consequently, the property rights associated with pension assets are set at a par with the property rights of other financial instruments. By contrast, the 1990s wave of privatizations, with governments in a role of collecting contributions from workers and transferring these to pension funds, made the funded pillars merely an element of a social contract rather than a proper financial instrument. 


\section{References}

Aaron, H.: 1966, The social insurance paradox, The Canadian Journal of Economics and Political Science/Revue canadienne d'Economique et de Science politique 32(3), 371-374.

Belan, P. and Pestieau, P.: 1999, Privatizing social security: A critical assessment, The Geneva Papers on Risk and Insurance Issues and Practice 24(1), 114-130.

Boadway, R. W. and Wildasin, D. E.: 1989a, A median voter model of social security, International Economic Review pp. 307-328.

Boadway, R. and Wildasin, D.: 1989b, Voting models of social security determinatio, Contributions to Economic Analysis, Vol. 179, Elsevier, pp. 29-50.

Boldrin, M. and Rustichini, A.: 2000, Political Equilibria with Social Security, Review of Economic Dynamics 3(1), 41-78.

Boll, S., Raffelhüschen, B. and Walliser, J.: 1994, Social security and intergenerational redistribution: A generational accounting perspective, Public Choice 81(1-2), 79-100.

Bonoli, G. and Shinkawa, T.: 2006, Ageing and pension reform around the world: evidence from eleven countries, Edward Elgar Publishing.

Borgers, T.: 2004, Costly voting, American Economic Review 94(1), 57-66.

Breyer, F.: 1989, On the intergenerational Pareto efficiency of pay-as-you-go financed pension systems, Journal of Institutional and Theoretical Economics (JITE)/Zeitschrift für die gesamte Staatswissenschaft 145(4), 643-658.

Browning, E. K.: 1975, Why the social insurance budget is too large in a democracy, Economic Inquiry 13(3), 373-388.

Butler, M.: 2000, The political feasibility of pension reform options: the case of Switzerland, Journal of Public Economics 75(3), 389-416.

Butler, M.: 2002, Tax-benefit linkages in pension systems: A note, Journal of Public Economic Theory 4(3), 405-415.

Casamatta, G., Cremer, H. and Pestieau, P.: 2001, Demographic shock and social security: A political economy perspective, International Tax and Public Finance 8(4), 417-431.

Chakravarty, S., Kaplan, T. R. and Myles, G.: 2018, When costly voting is beneficial, Journal of Public Economics 167, 33 - 42 .

Chlon, A., Gora, M. and Rutkowski, M.: 1999, Shaping pension reform in Poland: security through diversity, Social Protection Discussion Papers 20852, The World Bank.

Conde-Ruiz, J. I. and Galasso, V.: 2005, Positive arithmetic of the welfare state, Journal of Public Economics 89(5-6), 933-955. 
Conesa, J. C. and Garriga, C.: 2008, Optimal fiscal policy in the design of social security reforms, International Economic Review 49(1), 291-318.

Conesa, J. C. and Krueger, D.: 1999, Social Security Reform with Heterogeneous Agents, Review of Economic Dynamics 2(4), 757-795.

Congleton, R., Batinti, A., Bose, F., Kim, Y. and Pietrantonio, R.: 2013, Public choice and the modern welfare state, Edward Elgar Publishing, pp. 362-381.

Cooley, T. F. and Soares, J.: 1996, Will social security survive the baby boom?, Carnegie-Rochester Conference Series on Public Policy 45(1), 89-121.

Cooley, T. F. and Soares, J.: 1999a, A positive theory of social security based on reputation, Journal of Political Economy 107(1), 135-160.

Cooley, T. F. and Soares, J.: 1999b, Privatizing social security, Review of Economic Dynamics 2, 731755.

Davies, J. B., Sandström, S., Shorrocks, A. and Wolff, E. N.: 2011, The Level and Distribution of Global Household Wealth, Economic Journal 121(551), 223-254.

de Walque, G.: 2005, Voting on pensions: A survey, Journal of Economic Surveys 19(2), 181-211.

Dhami, S. and al Nowaihi, A.: 2010, Redistributive policies with heterogeneous social preferences of voters, European Economic Review 54(6), 743-759.

Fehr, H.: 2009, Computable stochastic equilibrium models and their use in pension-and ageing research, De Economist 157(4), 359-416.

Fisman, R., Jakiela, P. and Kariv, S.: 2017, Distributional preferences and political behavior, Journal of Public Economics 155, 1-10.

Galasso, V. and Profeta, P.: 2002, The political economy of social security: a survey, European Journal of Political Economy 18(1), 1-29.

Ghosal, S. and Lockwood, B.: 2009, Costly voting when both information and preferences differ: is turnout too high or too low?, Social Choice and Welfare 33(1), 25-50.

Gruber, J. and Wise, D. A.: 2009, Social security programs and retirement around the world: Fiscal implications of reform, University of Chicago Press.

Hagemejer, J., Makarski, K. and Tyrowicz, J.: 2015, Unprivatizing the pension system: the case of Poland, Applied Economics 47(8), 833-852.

Hénin, P.-Y. and Weitzenblum, T.: 2005, Welfare effects of alternative pension reforms: Assessing the transition costs for French socio-occupational groups, Journal of Pension Economics and Finance 4(03), 249-271.

Holzman, R. and Stiglitz, J. E.: 2001, New ideas about old age security, Washington, DC: World Bank. 
Huang, H., Imrohoglu, S. and Sargent, T. J.: 1997, Two computations to fund social security, Macroeconomic Dynamics 1(01), 7-44.

Jarrett, P.: 2011, Pension reforms in Poland and elsewhere: The view from Paris, CASE Network Studies and Analyses 425, CASE-Center for Social and Economic Research.

Kelley, D. G.: 2014, The political economy of unfunded public pension liabilities, Public Choice 158(12), 21-38.

Kindermann, F. and Krueger, D.: 2014, High Marginal Tax Rates on the Top 1\%? Lessons from a Life Cycle Model with Idiosyncratic Income Risk, NBER Working Papers 20601, National Bureau of Economic Research, Inc.

Krieger, T. and Ruhose, J.: 2013, Honey, I shrunk the kids' benefits - revisiting intergenerational conflict in OECD countries, Public Choice 157(1-2), 115-143.

Makarski, K., Tyrowicz, J. and Hagemejer, J.: 2017, Efficiency of the pension reform: the welfare effects of various fiscal closures, Macroeconomic Dynamics 21, 1205-1234.

McGrattan, E. R. and Prescott, E. C.: 2013, On financing retirement with an aging population, NBER Working Paper 18760, National Bureau of Economic Research.

Mulligan, C. B. and Sala-i Martin, X.: 2015, Political and economic forces sustaining social security, The B.E. Journal of Economic Analysis \& Policy 4(1), 1-56.

Orszag, P. R. and Stiglitz, J. E.: 2001, Rethinking pension reform: Ten myths about social security systems, in R. Holzman and J. E. Stiglitz (eds), New ideas about old age security, Washington, DC: World Bank, pp. 17-56.

Parlevliet, J.: 2017, What drives public acceptance of reforms? Longitudinal evidence from a Dutch pension reform, Public Choice 173(1-2), 1-23.

Phelan, C.: 2006, Public trust and government betrayal, Journal of Economic Theory 130(1), 27-43.

Samuelson, P. A.: 1958, An exact consumption-loan model of interest with or without the social contrivance of money, Journal of Political Economy 66(6), 467-482.

Schmitt-Grohe, S. and Uribe, M.: 2003, Closing small open economy models, Journal of International Economics 61(1), 163-185.

Schwartz, A. M.: 2014, The Inverting Pyramid: Pension Systems Facing Demographic Challenges in Europe and Central Asia, World Bank Publications, pp. 34-40.

Schwarz, A. M.: 2011, New realities of pension policy in central europe, Pension systems in emerging Europe: Reform in the age of austrerity. The conference organized by the European Bank for Reconstruction and Development on April 1st, 2011, in Paris.

Sjoblom, K.: 1985, Voting for social security, Public Choice 45(3), 225-240. 
Song, Z., Storesletten, K., Wang, Y. and Zilibotti, F.: 2015, Sharing high growth across generations: pensions and demographic transition in china, American Economic Journal: Macroeconomics $7(2), 1-39$.

Tabellini, G.: 2000, A positive theory of social security, Scandinavian Journal of Economics $\mathbf{1 0 2}(3), 523-545$. 


\section{A Proofs (not intended for publication; online dissemination)}

Lemma 1. If $\theta_{t-1}=2$ and $\theta_{t}=1$, i.e., asset capture and shifting of contributions occurs (denoted by superscript $A C$ ), lump-sum taxes $\Upsilon_{t}$ in period $t$ are lowered by

$$
-\Delta \Upsilon_{t}^{A C}=\tau^{F} w_{t}\left(\frac{3+r+2 g}{3(1+g)}-\frac{r-g}{3(1+r)}\right)>0
$$

Proof. Proof of Lemma 1. Recall Assumption 1: for $\theta_{t-1}=2$ and $\theta_{t}=1, f_{1, t}^{F}=0$ and $f_{2, t}^{F}=$ $(1+r) \tau^{F} w_{t-1}$. From equation (4), the government balance adjusts by:

$$
-\sum_{j} \Delta \Upsilon_{t}^{A C}=\sum_{j=1}^{J-1}\left(f_{j, t}+\tau^{F} w_{t}\right)-\frac{(1+g)(1+r) \tau^{F} w_{t-1}-(1+g)(1+g) \tau^{F} w_{t-1}}{(1+r)}
$$

Using that the total population alive has size 3 and that $w_{t}=w_{t-1}(1+g)$,

$$
-3 \Delta \Upsilon_{t}^{A C}=\left((1+r) \tau^{F} w_{t-1}+(1+1) \tau^{F} w_{t}\right)-\frac{(r-g)(1+g) \tau^{F} w_{t-1}}{1+r}
$$

Simplifying

$$
-3 \Delta \Upsilon_{t}^{A C}=\tau^{F} w_{t}\left(\frac{3+r+2 g}{1+g}-\frac{r-g}{1+r}\right)>0
$$

Lemma 2. If $\theta_{t-1}=2$ and $\theta_{t}=0$, i.e., the pension system is abandoned completely (denoted by superscript A), lump-sum taxes $\Upsilon_{t}$ in period t are lowered by

$$
-\Delta \Upsilon_{t}^{A}=\frac{3+r+2 g}{3(1+g)} \tau^{F} w_{t}>0
$$

Proof. Proof of Lemma 2. Recall Assumption 1: for $\theta_{t-1}=2$ and $\theta_{t}=0, f_{1, t}^{F}=0$ and $f_{2, t}^{F}=$ $(1+r) \tau^{F} w_{t-1}$. From equation (4), the government balance adjusts by:

$$
-\sum_{j} \Delta \Upsilon_{t}^{A}=\sum_{j}^{J-1}\left(f_{j, t}+\tau^{F} w_{t}\right)
$$

Using that the total population size alive is 3 and that $w_{t}=w_{t-1}(1+g)$, and simplifying:

$$
-3 \Delta \Upsilon_{t}^{A}=\frac{3+r+2 g}{1+g} \tau^{F} w_{t}>0
$$


Proof. Proof of Proposition 1. Recall that superscript $P$ denotes PAYG pensions and that contributions are denoted by $\tau$. We also use that $w_{t}=(1+g) w_{t-1}$. Abandoning the pension system implies zero pension system contributions and zero pension payments. Hence, the PAYG pillar disappears. In such a case, taxes are unaffected.

- The budget constraint of an individual born in period $t$ is

$$
c_{1, t}+\frac{c_{2, t+1}}{(1+r)}+\frac{c_{3, t+2}}{(1+r)^{2}}=(1-\tau) w_{t}-\Upsilon_{t}+\frac{(1-\tau) w_{t+1}-\Upsilon_{t+1}}{(1+r)}+\frac{b_{t+2}^{P}-\Upsilon_{t+2}}{(1+r)^{2}}
$$

The resource effect of abolishing the pension pillar is given by

$$
\tau w_{t}+\frac{\tau(1+g) w_{t}}{(1+r)}-\frac{b_{t+2}^{P}}{(1+r)^{2}}=\frac{(2+r+g)(1+r)-(2+g+g)(1+g)}{(1+r)^{2}} \tau w_{t} .
$$

This expression is positive, if $r>g$. Hence, young agents would benefit from abandoning the PAYG pension system. Thus, young agents vote to abandon it.

- The budget constraint of a middle-aged individual can be expressed as

$$
c_{2, t}+\frac{c_{3, t+1}}{(1+r)}=(1+r) a_{1, t-1}+(1-\tau) w-\Upsilon_{t}+\frac{b_{t+1}^{P}-\Upsilon_{t+1}}{(1+r)}
$$

If there was no pension system, the resource effect would be given by:

$$
\tau w_{t}-\frac{b_{t+1}^{P}}{(1+r)}=\frac{r-1-2 g}{1+r} \tau w_{t}
$$

which is negative if $r<1+2 g$. Therefore, for plausible values of $r$ and $g$, middle-aged agents lose from abandoning the PAYG pension system, so they vote to keep it.

- The budget constraint of an old individual can be expressed as $c_{3, t}=(1+r) a_{2, t-1}+b_{t}^{P}-\Upsilon_{t}$. Abandoning the pension system implies a loss of resources of $b_{t}^{P}>0$. Thus old agents would lose from abandoning the PAYG pension system. Thus old agents vote to keep it.

- Old and middle-aged agents outnumber the young, so the PAYG system is stable. 
Proof. Proof of Proposition 2. We show that keeping the system intact cannot be an equilibrium strategy, i.e. voters systematically prefer asset capture.

- The budget constraint of a young individual is:

$$
c_{1, t}+\frac{c_{2, t+1}}{(1+r)}+\frac{c_{3, t+2}}{(1+r)^{2}}=(1-\tau) w_{t}-\Upsilon_{t}+\frac{(1-\tau) w_{t+1}-\Upsilon_{t+1}}{(1+r)}+\frac{b_{t+2}-\Upsilon_{t+2}}{(1+r)^{2}},
$$

and assets capture lowers their pension by

$$
\Delta b_{t+2}=(r-g)(3+2 g+r) \tau^{F} w_{t}
$$

Compare the loss in terms of pensions with the taxes reduced $\left(\Delta \Upsilon_{t}^{A C}\right)$ as per equation (A.1). The young individual supports asset capture if:

$$
\begin{aligned}
& \Delta \Upsilon_{t}^{A C} \stackrel{?}{>}-\frac{\Delta b_{t+2}}{(1+r)^{2}} \Longleftrightarrow \frac{3+2 g+r}{3(1+g)} \tau^{F} w_{t}-\frac{(r-g)}{3(1+r)} \tau^{F} w_{t} \stackrel{?}{>} \frac{(r-g)}{(1+r)^{2}}(3+2 g+r) \tau^{F} w_{t} \\
& (3+r+2 g)(1+r)^{2}>3(r-g)(1+g)(3+2 g+r)+(r-g)(1+r)(1+g)
\end{aligned}
$$

which holds $\forall \quad r, g>0 .{ }^{26}$

- The budget constraint of a middle-aged individual is expressed as

$$
c_{2, t}+\frac{c_{3, t+1}}{(1+r)}=(1+r) a_{1, t-1}+\left(1-\tau_{t}\right) w_{t}-\Upsilon_{t}+\frac{b_{t+1}-\Upsilon_{t+1}}{(1+r)},
$$

and assets capture lowers their pension by

$$
\Delta b_{t+1}=\frac{(r-g)(2+r+g)}{1+g} \tau^{F} w_{t}
$$

Analogously to the young individual, we use equation (A.1) to compare the gain from lowered taxes due to the asset capture with the decline in pension benefits:

$$
\Delta \Upsilon_{t}^{A C} \stackrel{?}{>}-\frac{\Delta b_{t+1}}{1+r} \Longleftrightarrow(1+r)(3+r+2 g) \stackrel{?}{>}(r-g)(7+3 r+4 g)
$$

The above inequality depends essentially on the magnitude of $r-g \cdot{ }^{27}$

- Finally, the budget constraint of an old individual is $c_{3, t}=(1+r) a_{2, t-1}+b_{t}-\Upsilon_{t}$. As assets capture does not affect their pension $\left(\Delta b_{t}=0\right)$, using Lemma 1 it is clear that the old gain from asset capture.

Summarizing, old and young individuals vote to capture assets, so even if middle-aged individuals vote against asset capture, they are outvoted. Hence, a system with a funded pillar is unstable.

\footnotetext{
${ }^{26}$ The computations yield a third-order polynomial in both $r$ and $g$, which takes positive values as long as $r>0$ and $g>0$.

${ }^{27}$ If $r-g$ is sufficiently small the middle-aged individual votes to capture assets, otherwise they are in favor of maintaining the status quo. Note that a small difference between $r$ and $g$ is equivalent to a small gain of having a funded pension system over having a PAYG pension system.
} 
Proof. Proof of Proposition 3. We are going to show that voting results in the following rule for pension systems: $\theta_{t}=\theta\left(\theta_{t-1}\right)=1$ for $\theta_{t} \in\{1,2\}$. Note that by Assumption 1, if there is no pension system, then it cannot be introduced, i.e. $\theta_{t}=\theta\left(\theta_{t}\right) \in\{0\}$ for $\theta_{t}=0$ and $\theta_{t}=\theta\left(\theta_{t}\right) \in\{0,1\}$ for $\theta_{t}=1$. Following the one-shot deviation principle we need to show that for $\theta_{t} \in\{1,2\}$ an agent finds one shot deviation from equilibrium policy not optimal.

We first start with the case of $\theta_{t-1}=2$.

The basic idea of our proof is summarized in Table A.1. For $\theta_{t-1}=2$, Table A.1 shows that the order in which policy alternatives are considered does not affect the results and voters always capture assets and shift contributions.

Table A.1: Voting on policies in pairs, $\theta_{t-1}=2$

\begin{tabular}{l|c|c|c|c}
\hline policies $\backslash$ agent & $j=1$ & $j=2$ & $j=3$ & Preferred outcome (=voting) \\
\hline \hline no capture $\theta_{t}=2$ vs capture $\theta_{t}=1$ & $\theta_{t}=1$ & $\theta_{t}=2$ & $\theta_{t}=1$ & $\theta_{t}=1$ \\
\hline abandon $\theta_{t}=0$ vs capture $\theta_{t}=1$ & $?$ & $\theta_{t}=1$ & $\theta_{t}=1$ & $\theta_{t}=1$ \\
\hline abandon $\theta_{t}=0$ vs no capture $\theta_{t}=2$ & $?$ & $\theta_{t}=2$ & $\theta_{t}=2$ & $\theta_{t}=2$ \\
\hline \hline
\end{tabular}

- First, we check preferences across generations towards asset capture $\theta_{t}=1$ vs no asset capture $\theta_{t}=2$. In this case, a one-period deviation would be not capturing asset today and capturing assets tomorrow, as equilibrium policy predicts; recall that equilibrium policy is $\theta_{t}=\theta\left(\theta_{t-1}\right)=1$ for $\theta_{t-1} \in\{1,2\}$.

- The budget constraint of a young individual is expressed as:

$$
c_{1, t}+\frac{c_{2, t+1}}{(1+r)}+\frac{c_{3, t+2}}{(1+r)^{2}}=(1-\tau) w_{t}-\Upsilon_{t}+\frac{(1-\tau) w_{t+1}-\Upsilon_{t+1}}{(1+r)}+\frac{b_{t+2}-\Upsilon_{t+2}}{(1+r)^{2}}
$$

In other words, not capturing assets this period means that they are captured next period. Pensions of young are increased by

$$
\Delta b_{t+2}=(1+g)(r-g) \tau^{F} w
$$

Since rather than in period $t$, taxes are lowered in period $t+1$, the present value of lower taxes is reduced by $-\left(-\Delta \Upsilon_{t}^{A C}\right)+\frac{-\Delta \Upsilon_{t+1}^{A C}}{1+r}$. Combining with equation (A.1) and simplifying:

$$
-\left(-\Delta \Upsilon_{t}^{A C}\right)+\frac{-\Delta \Upsilon_{t+1}^{A C}}{1+r}+\frac{\Delta b_{t+2}}{(1+r)^{2}}<0 \Longleftrightarrow 1+g<1+r
$$

which holds for all $r>g>0$. Higher pensions due to postponing asset capture do not compensate for the postponement of the tax cut. Thus, the young individuals prefer asset capture.

- For old individuals, asset capture in the next period brings no value, hence they prefer to capture assets immediately (they do not find a one-time deviation towards no asset capture optimal).

- With young and old individuals voting in favor of asset capture, the preference of middle- 
aged individuals is irrelevant for the voting outcome. The budget constraint of a middleaged individual is

$$
c_{2, t}+\frac{c_{3, t+1}}{(1+r)}=(1+r) a_{1, t-1}+\left(1-\tau_{t}\right) w_{t}-\Upsilon_{t}+\frac{b_{t+1}-\Upsilon_{t+1}}{(1+r)}
$$

Postponing assets capture increases their pension by $\Delta b_{t+1}=(r-g)(2+r+g) \tau^{F} w$. Compare the gain in pension benefits with the loss of postponing the lowering of the taxes:

$$
-\left(-\Delta \Upsilon_{t}^{A C}\right)+\frac{-\Delta \Upsilon_{t+1}^{A C}}{1+r}+\frac{\Delta b_{t+1}}{(1+r)}>0 \Longleftrightarrow 2+2 g+2 r g>2 g^{2}
$$

Therefore, for $1+2 g>r>g$, middle-aged individuals vote not to capture assets.

- Second, we check preferences across generations towards complete abandonment of the pension system $\theta_{t}=0$ vs asset capture $\theta_{t}=1$. We are comparing abandoning the complete pension system today vs capturing assets today. Recall that once the pension system has been completely abandoned, it cannot be restored; see Assumption 1. We show that middle-aged and old individuals prefer asset capture to completely abandoning the pension system.

- The budget constraint of a young individual is

$$
c_{1, t}+\frac{c_{2, t+1}}{(1+r)}+\frac{c_{3, t+2}}{(1+r)^{2}}=\left(1-\tau_{t}\right) w_{t}-\Upsilon_{t}+\frac{\left(1-\tau_{t+1}\right) w_{t+1}-\Upsilon_{t+1}}{(1+r)}+\frac{b_{t+2}-\Upsilon_{t+2}}{(1+r)^{2}} .
$$

Equations (A.1) and (A.2) imply that abandoning the pension system completely has the following effect on the present discounted value of resources of:

$$
\begin{aligned}
& -\Delta \Upsilon_{t}^{A}-\left(-\Delta \Upsilon_{t}^{A C}\right)+\tau w_{t}+\frac{\tau w_{t+1}}{(1+r)}-\frac{b_{t+2}}{(1+r)^{2}} \\
& =\frac{(r-g)}{3(1+r)} \tau^{F} w+\left(\frac{(2+r+g)(1+r)}{(1+r)^{2}}-\frac{2(1+g)^{2}}{(1+r)^{2}}\right) \tau w .
\end{aligned}
$$

If $r>g$, the young individual prefer to abandon the pension system.

- The budget constraint of a middle-aged agent can be expressed as

$$
c_{2, t}+\frac{c_{3, t+1}}{(1+r)}=(1+r) a_{1, t-1}+(1-\tau) w_{t}-\Upsilon_{t}+\frac{b_{t+1}-\Upsilon_{t+1}}{(1+r)}
$$

The difference is, using equations (A.1) and (A.2):

$$
-\Delta \Upsilon_{t}^{A}-\left(-\Delta \Upsilon_{t}^{A C}\right)+\tau w_{t}-\frac{b_{t+1}}{(1+r)}=\frac{(r-1-2 g)}{(1+r)} \tau^{P} w+\frac{r-3-4 g}{3(1+r)} \tau^{F} w
$$

Therefore, for $r<1+2 g$ middle-aged individuals prefer to capture assets rather than abandon pension system completely.

- The budget constraint of an old individual is $c_{3, t}=(1+r) a_{2, t-1}+b_{t}-\Upsilon_{t}$. Abandoning the pension system deprives them of their pensions, hence they experience an effect on their resources of $-b_{t}<0$. Therefore, they prefer to capture assets rather than abandoning the pension system completely. 
- Third, we check preferences across generations towards keeping the pensions system intact this period (and capturing assets in the next period) $\theta_{t}=2$ vs abandonment of pension system $\theta_{t}=0$. In this case we compare two one-period deviations. One is not capturing assets today and the second is completely abandoning pension system today. Once a pension system is completely abandoned, it cannot be restored. Such a policy is followed by no pension system (according to equilibrium policy). We show that old- and middle-aged individuals prefer to capture assets, so they outvote the young individuals.

- The budget constraint of a young individual is given by:

$$
c_{1, t}+\frac{c_{2, t+1}}{(1+r)}+\frac{c_{3, t+2}}{(1+r)^{2}}=(1-\tau) w_{t}-\Upsilon_{t}+\frac{(1-\tau) w_{t+1}-\Upsilon_{t+1}}{(1+r)}+\frac{b_{t+2}-\Upsilon_{t+2}}{(1+r)^{2}} .
$$

Completely abandoning the pension system in period $t$ means that they lose future pensions and future lower taxation, but gain contributions from period $t$ and $t+1$ as well as experience lower taxes in period $t$. Using equations (A.1) and (A.2), the budget constraint is affected as follows:

$$
\begin{aligned}
& \tau w_{t}+\frac{\tau w_{t+1}}{(1+r)}-\frac{b_{t+2}}{(1+r)^{2}}+\left(-\Delta \Upsilon_{t}^{A}\right)-\frac{\left(-\Delta \Upsilon_{t+1}^{A C}\right)}{(1+r)} \\
& =\tau^{F} w_{t} \frac{r-g}{3(1+r)^{2}}\left(\frac{g(2+g)-r(2(2+g)+r)-1}{(1+g)(1+r)}\right)+\tau^{P} w_{t}\left(\frac{r(3+r)-g(3+2 g-r)}{(1+r)^{2}}\right)
\end{aligned}
$$

which is positive for $r>g$, so young agents prefer abandoning the pension system to capturing assets.

- The budget constraint of a middle-aged individual is

$$
c_{2, t}+\frac{c_{3, t+1}}{(1+r)}=(1+r) a_{1, t-1}+\left(1-\tau_{t}\right) w_{t}-\Upsilon_{t}+\frac{b_{t+1}-\Upsilon_{t+1}}{(1+r)}
$$

Completely abandoning the pension system in period $t$ means that they lose future pensions and future lower taxation, but gain contributions from period $t$ as well as experience lower taxes in period $t$. Using equations (A.1) and (A.2), the budget constraint is affected as follows:

$$
\begin{aligned}
& \tau w_{t}-\frac{b_{t+1}}{(1+r)}+\left(-\Delta \Upsilon_{t}^{A}\right)-\frac{\left(-\Delta \Upsilon_{t+1}^{A C}\right)}{(1+r)} \\
& =\tau^{F} w_{t}\left(1-\frac{2+r+g}{1+g}+\frac{r-g}{3(1+r)}\left(\frac{2+g^{2}-r(4+r+2 g)}{(1+g)(1+r)}\right)\right)+\tau^{P} w_{t}\left(\frac{r-1-2 g}{1+r}\right)
\end{aligned}
$$

Since $0<g<r<1+2 g$, this expression implies that middle-aged individuals prefer to capture assets rather than abandon pension system altogether.

- Old agents clearly prefer to capture assets rather than abandon the pension system.

The case of $\theta_{t-1}=1$.

It follows from Proposition 1 that voting results in $\theta_{t}=\theta\left(\theta_{t-1}\right)=1$ for $\theta_{t-1}=1$. 


\section{B Calibration (not for publication; for online dissemination only)}

Figure B.1: Number of 20-year-old arriving in each period (left), mortality rates over time for a selected cohort (middle) and labor-augmenting technological progress (right).
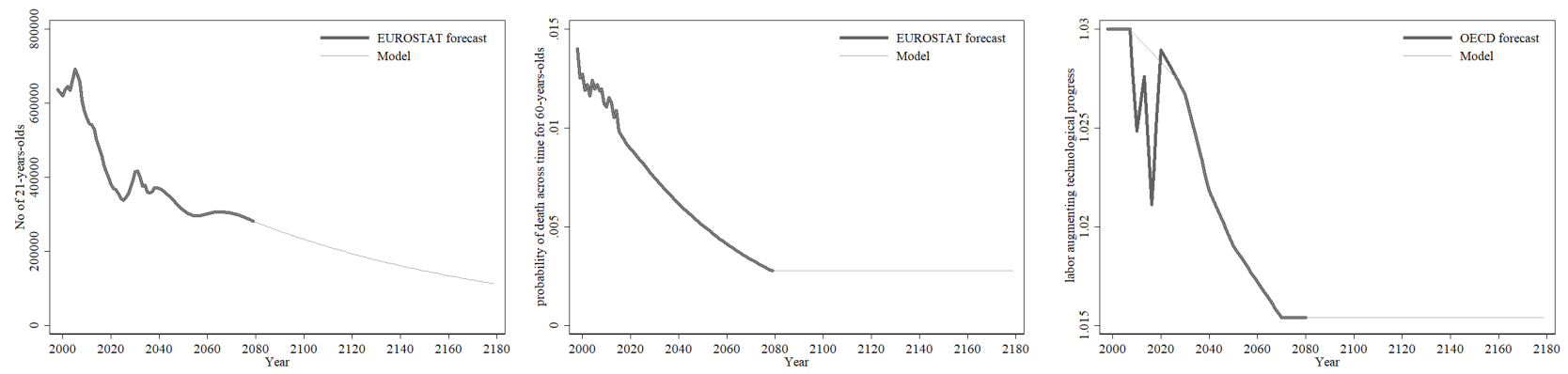

Source: Demographic forecasts until 2080 are based on EUROSTAT, rate of technological progress is based on the forecasts of the Ageing Working Group of the Economic Policy Committee and the European Commission, and the TFP data represented by the thick solid line are from the OECD. The latter are smoothed by a moving-average for the cyclical component.

Figure B.2: Distribution of $\omega$ multipliers (left) and $\phi$ multipliers (right).
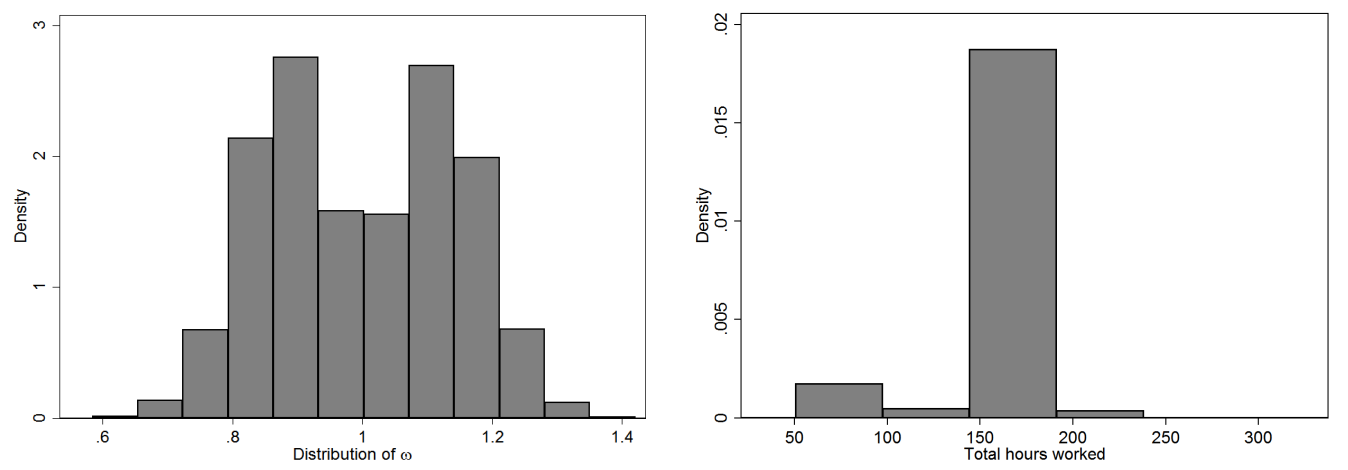

Notes: Estimates of the distribution are obtained using data from the Structure of Earnings Survey, wave of 1998.

Figure B.3: Interest rate and growth rate of total wage bill in no policy change scenario.

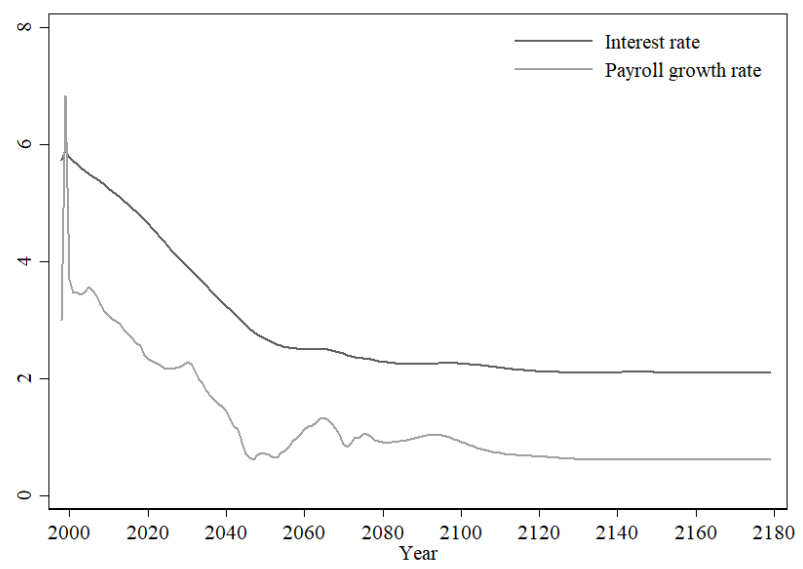




\section{Introducing the two-pillar DC system (not for publication; for online dissemination only)}

Replacing a PAYG-DB pension system with a DC system with partial funding has by construction differentiated effects across cohorts and within subcohorts. Based on welfare evaluations, which account for direct and general equilibrium effects, we can demonstrate which subcohorts are in support of turning the PAYG-DB system into a DC system with partial funding. While under PAYGDB individuals view their pension contributions as taxes, DC allows for a direct link between the individual's pension contributions and her future pension benefits. This boosts the individual's labor supply and, hence, current and future pension benefits.

This result prevails regardless of the individual preferences and the productivity endowment. Among the transition cohorts, i.e., those younger than 40 years in 1999, nearly all subcohorts experience a decline in welfare due to lower pension benefits and higher taxation. The fall in pensions arises, because in the initial system there is already a deficit and with longevity it becomes even larger. The reform from PAYG-DB to PAYG-DC balances the system by construction. Hence, with the same contribution rate pensions decline. The exception from the decline in welfare are the most patient transition subcohorts. In fact, there appears to be no room for a coalition based on individual productivity endowments, because the general equilibrium effects as well as tax effects dominate the direct effects for both the initially old cohorts and the transition cohorts. In the long run all subcohorts gain due to significantly lower taxation. Overall, the aggregate welfare effect in terms of certaintyequivalent consumption amounts to $1 \%$ of lifetime consumption, so that if all losers were compensated by the winners, the latter would on net still gain (i.e., a Kaldor-Hicks welfare improvement). The results are portrayed in Figure C.4

Figure C.4: Cohort distribution of the welfare effects from introducing two-pillar DC system

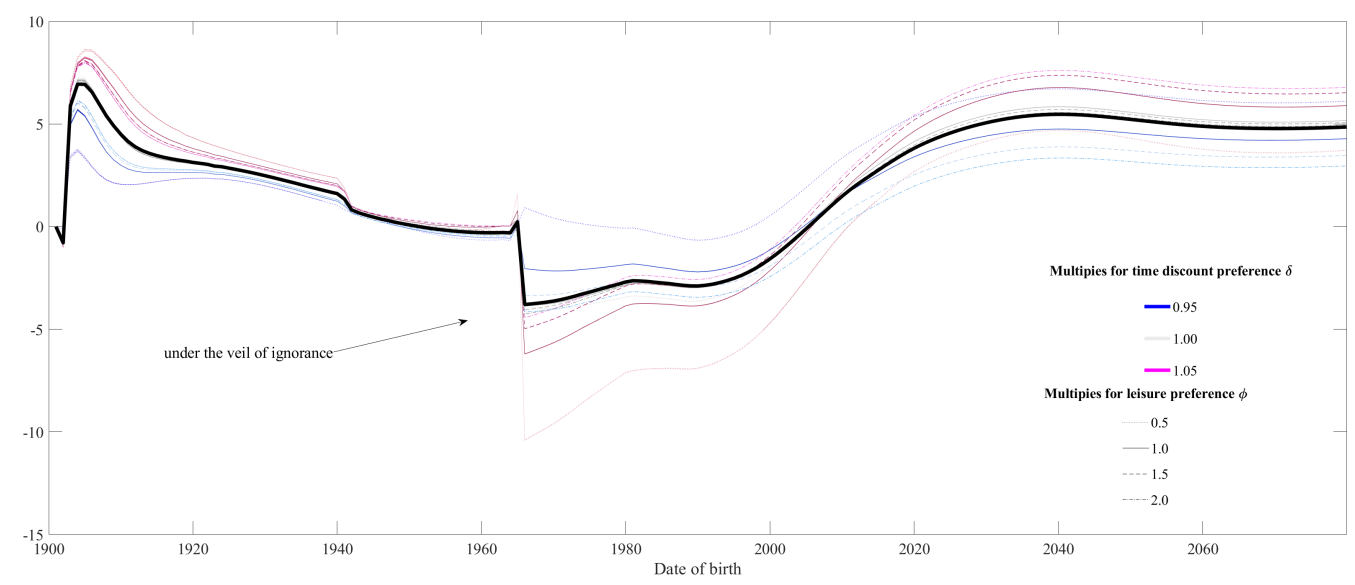

Note: Expressed in percent of certainty-equivalent consumption relative to continuation of the PAYG DB system. The driving force behind differences in the evaluation of reform is the difference in the subcohort discount factor $\delta_{\kappa}$ (distinguished by color). The leisure preference parameter $\phi_{\kappa}$ brings some diversity in the results (distinguished by line style). The initial productivity endowment has virtually no effect on the reform evaluation (for given subcohort discount factor and leisure preference, the lines overlap for all $\omega_{\kappa}$ ). We additionally report the consumption equivalents from simulation without intra-cohort heterogeneity (the black line). 
In principle, the DC system is much less redistributive than the DB system. Earlier literature hinted that the older cohorts, i.e. those retired at the moment of the pension system privatization, should have an incentive to form a coalition with the working-age low productivity agents. Here, we observe that this is not the case, because the fiscal adjustments accompanying the reform affect the welfare of agents to a greater extent than the potential gains from the redistribution. Indeed, the models of Cooley and Soares (1999a) and subsequent contributions abstract from fiscal adjustment, while often also the labor supply is assumed inelastic. Hence, the general equilibrium effects have less relevance in those stylized setups than in our setup. Note that individuals in our setup have access to a savings technology, hence a retirement system is not strictly necessary for consumption smoothing. This explains why the reception of the substantial change from the DB to the two-pillar DC system is relatively similar across cohorts.

This result is interesting not only because it is counter-intuitive, but also because it points to the relevance of the fiscal adjustments accompanying pension system reforms: if lump-sum taxes were used to finance the transition costs of the reform, the utility of the elderly cohorts would be harmed, thus revealing their strong opposition to the reform. However, the fiscal rule portrayed in equation (21) partly raises consumption taxes, but mostly smoothes the costs of the reform to the future generations via the public debt. Overall, the cohort distribution of these welfare effects is such that in 1999 approximately $54.7 \%$ of the population living at the moment of the reform would support it; see the left panel of Figure C.5. To obtain this decomposition, we subtract the welfare effects of PAYG DC from the total welfare effects of the reform, i.e. we run an additional simulation in which $\tau^{P A Y G}=\tau$ and $\tau^{F}=0$ and we compare the effect to the welfare from the scenario with partial privatization as described above. The effects of having the funded pillar are actually universally (i.e., for all subcohorts) negative for cohorts born until approximately 2010, when they become universally positive across cohorts, as shown in the right panel of Figure C.5. This implies that eventually the gains from a faster-growing and larger economy exceed the costs of financing the additional transitory gap in the public pension system.

The gradual introduction of the partially funded DC pension system is the baseline scenario for all the subsequent simulations. Figures C.4 and C.5 suggest that pension system privatization eventually improves welfare for newborn cohorts at the moment of their birth. The losing cohorts pass away whereas the newborn benefit from increased overall efficiency and lower taxation. Moreover, partial funding raises the welfare gains from having the DC system instead of the pure PAYG-DB system. 
Figure C.5: Political support for two-pillar system (left) and gains from funded pillar (right)
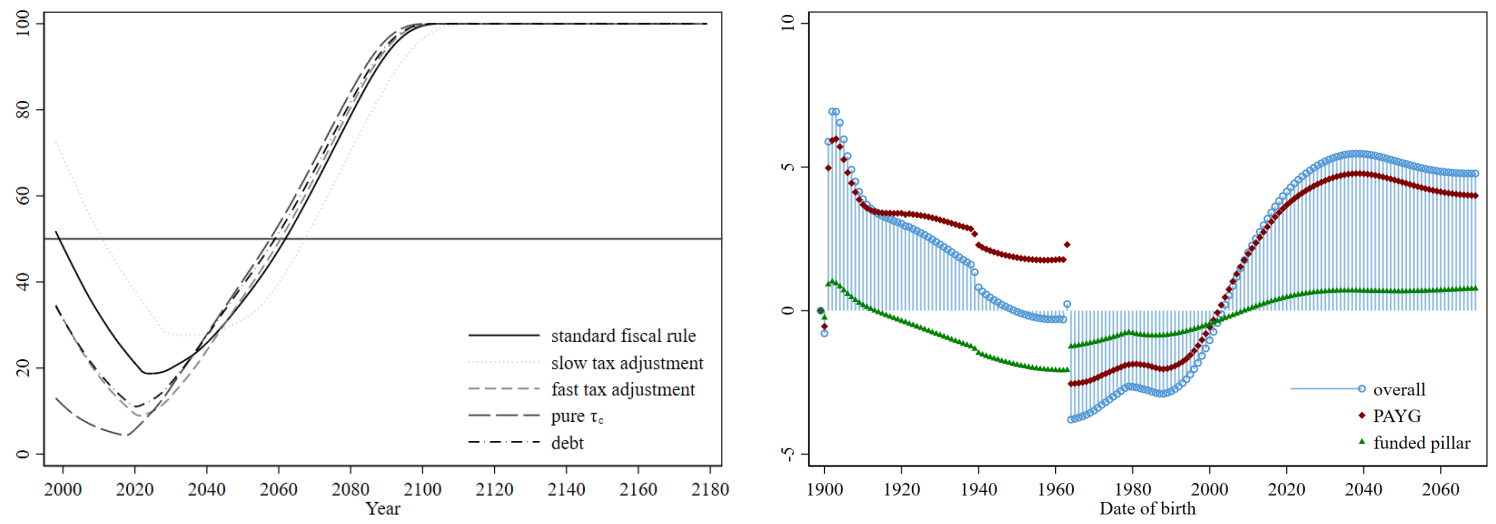

Note: The left-hand panel depicts as a function of the tax rule the percent of subcohorts living in each period who gain from introducing the two-pillar DC pension system, as described above. Hence, for each year on the horizontal axis it gives the percent of political support for the reform that took place in 1999. The solid black line, denoted as 'standard fiscal rule' refers to the fiscal rule as described by equation (21) and parametrized in Table 1. Alternative specifications include an instantaneous consumption tax adjustment (denoted as 'pure $\tau_{c}{ }^{\prime}$ ), full accommodation through public debt with subsequent reduction of debt after the transition is over, using the fiscal rule described in equation (21) (denoted as 'debt'), slower tax adjustment than described in Table 1 by setting parameter $\varrho_{D}$ to 0.03 in the fiscal rule (21) (denoted as 'slow tax adjustment'), and faster tax adjustment by setting parameter $\varrho_{D}$ to 0.75 in (21) (denoted as 'fast tax adjustment').

Figure C.6: Interest rates (left) and tax rates (right) under the DB and DC pension systems
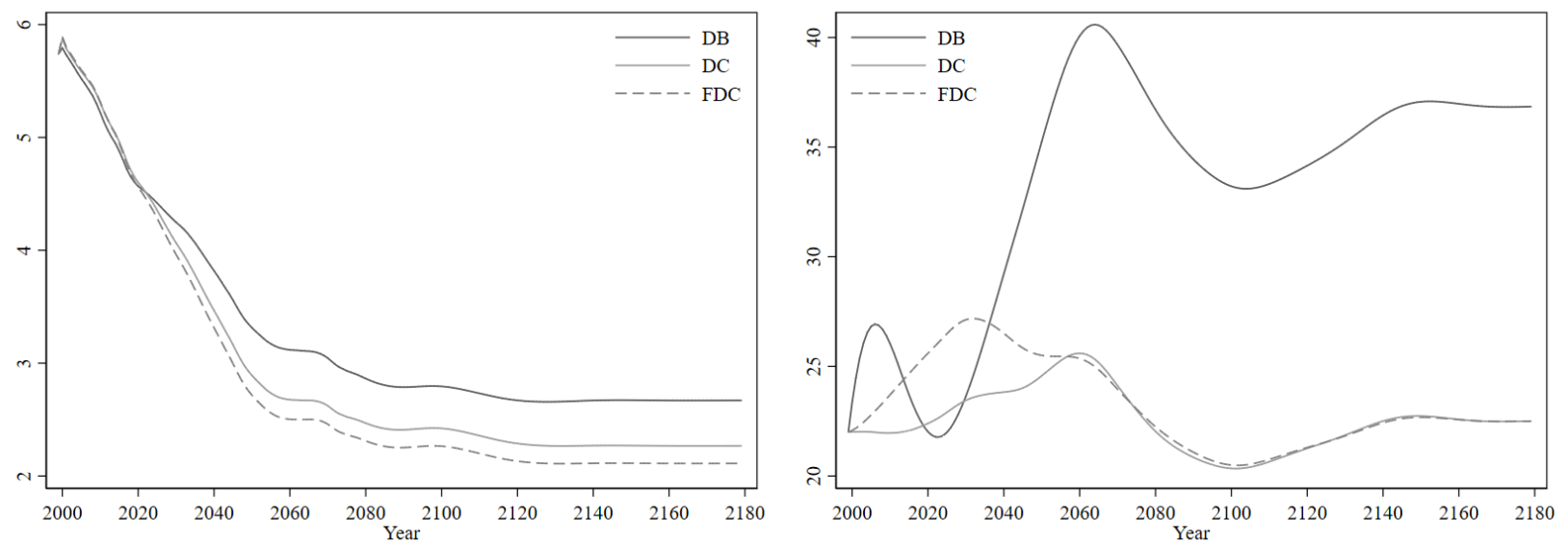

Notes: FDC denotes DC system with partial funding, while DC denotes a DC system financed entirely on a PAYG basis. DB denotes a defined-benefit system fully based on PAYG financing. The initial steady state is always the PAYG-DB system. Each line denotes a separate simulation, on an economy with the same initial steady-state calibration. In the scenarios of a change to defined-contribution (with or without funding) the reform is introduced unexpectedly in the first period since the start. The transition is gradual, as described in Section . 


\section{Macroeconomic effects of reducing the funded pension pillar}

As an example, we discuss the effects of capturing pension assets in 2012. This year is suitable for illustration purposes, because around this date most of the countries that earlier introduced partiallyfunded DC systems reduced their funded pillars. Results for other voting years are available upon request. Reducing the funded pillar improves fiscal stance in the short run, which translates into lower taxes over the medium run. This comes at the expense of lower pensions and slower capital accumulation, hence lower output and higher taxation, in the long run.

The impact of the three analyzed policies on pensions differs. Policy 1 redirects contributions from the funded pillar to the PAYG pillar. This shift lowers pension benefits for two reasons. First, because the interest rate exceeds the growth rate of the wage bill, during working age entitlements in the PAYG pillar accumulate at a lower rate than capital in the funded pillar. Second, pensions paid from the PAYG pillar are also indexed at a rate lower than pensions paid from the funded pillar. The effect is depicted in Figure B.3. In addition to the direct effect on pensions, there are also indirect effects through taxes. The shift of contributions reduces the deficit in the public pension fund and results in lower consumption taxes.

Policy 2 means that accumulated capital in the funded pillar is shifted to the PAYG system and used to finance current government expenditure. Similarly to Policy 1, the deficit is reduced in the PAYG pillar, which benefits current generations as it allows to reduce consumption tax rates. Ultimately, the fiscal cost of implicit debt is lower than that of the explicit debt, because there is no interest to pay on the implicit debt. It comes at the cost of lower benefits for cohorts working during the capturing of the assets. Unlike Policy 1, the appropriation is one-off and, hence, Policy 2 has no long-run effect.

In Policy 3, the effects of Policy 1 and Policy 2 add up: pension benefits are lower, and the decline in taxes is larger. In the long run, the effects of Policy 1 and Policy 3 are by construction the same. We portray the quantification in Figure D.7. The direct effects on consumption taxes are combined with indirect effects on overall capital taxation as depicted in Figures D.7c and D.7d). Lower pensions due to removal of funded pillar result in higher voluntary savings. However, since voluntary savings are taxed and cannot be converted into an annuity at retirement age, this increase fails to make up for the initial effect of the abolition of the funded pillar; see Figure D.9. Nevertheless, with the reaction of private voluntary savings, there is an increase in the overall capital income taxation.

The impact on the labor supply is twofold. First, lower consumption taxes distort less the intratemporal choice between consumption and leisure, which tends to increase the labor supply together with lower pensions. Second, the weakened link between the contribution and the eventual pension exerts a downward effect on the labor supply. Depending on which effect is stronger, the labor supply rises or falls. For Policy 1 the second effect dominates. The labor supply drops rapidly at the time of introducing the policy change. For Policy 2 the first effect is stronger, and the labor supply increases. In the case of Policy 3, the effect of lower consumption taxes dominates initially, as the decline in taxes is largest in the initial years after the reversal of the original reform, but over time this effect is overtaken by the effect of the distortion associated with the second effect; see Figure D.9. 
Figure D.7: The effect of reducing the funded pillar on pensions and fiscal variables

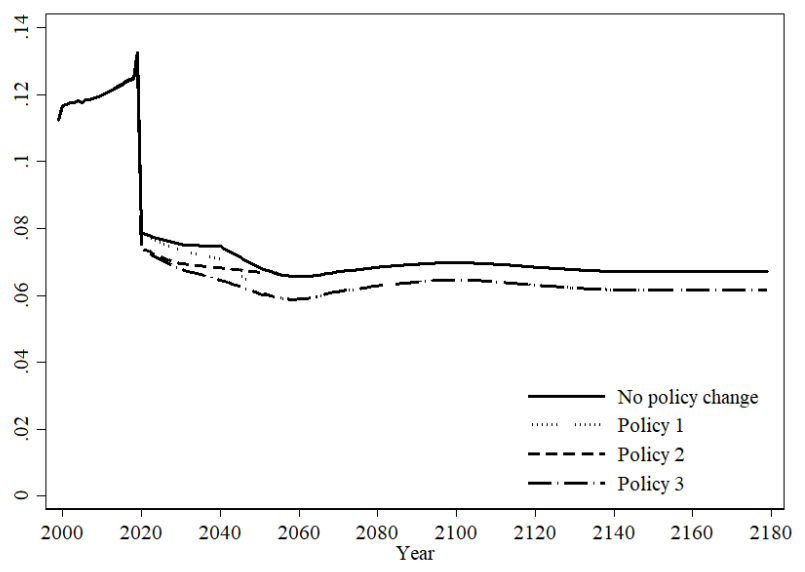

(a) Average pensions: level

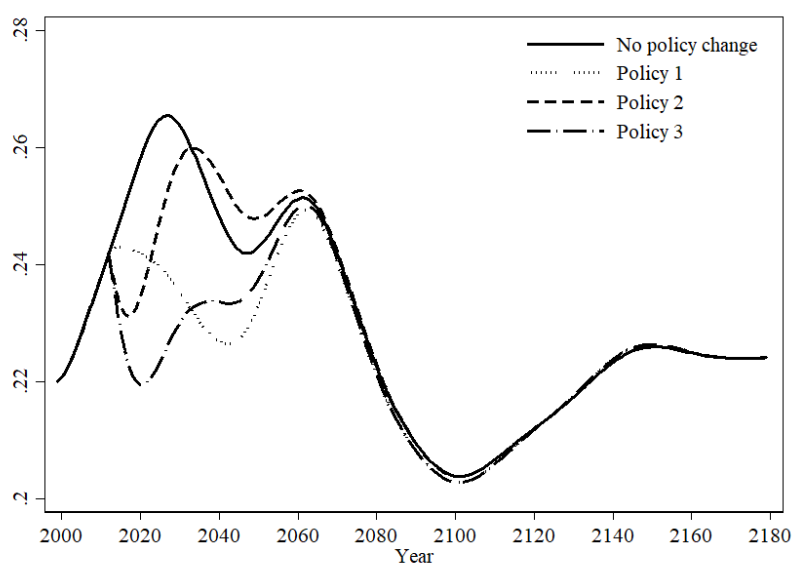

(c) Consumption taxes: level

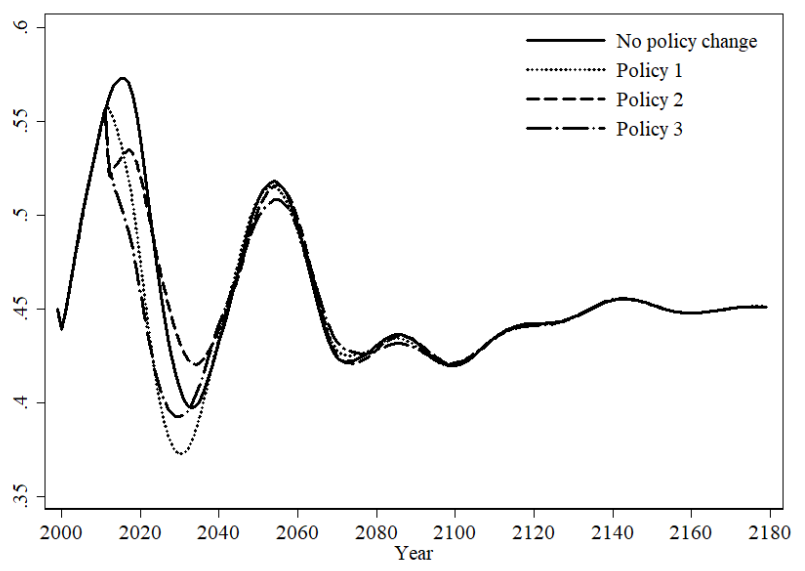

(e) Debt share in GDP: level

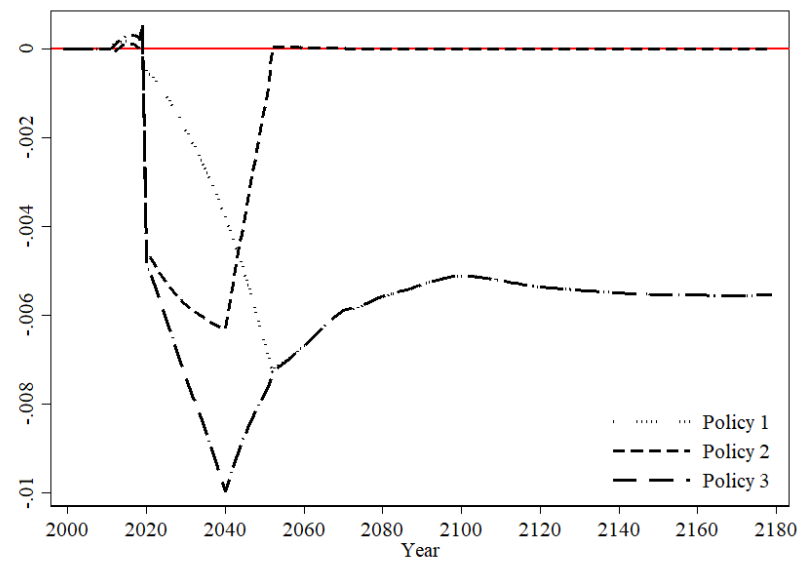

(b) Average pensions: relative to baseline

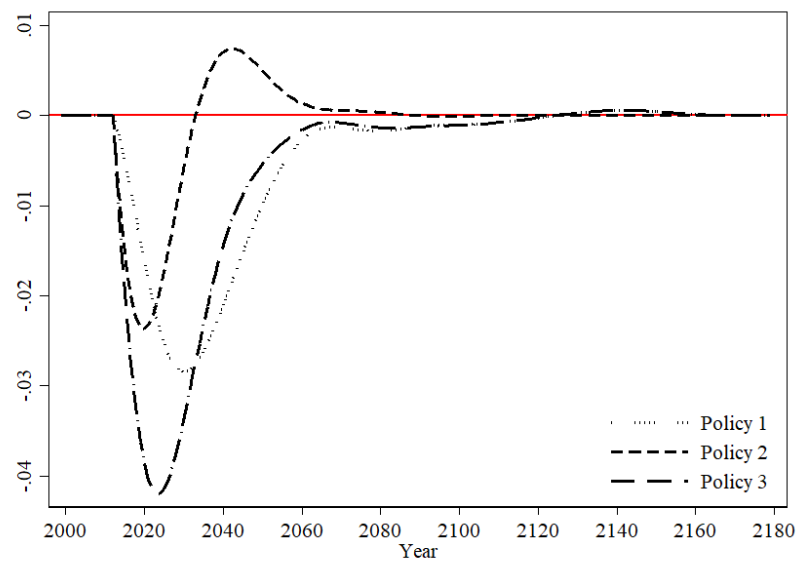

(d) Consumption taxes: relative to baseline

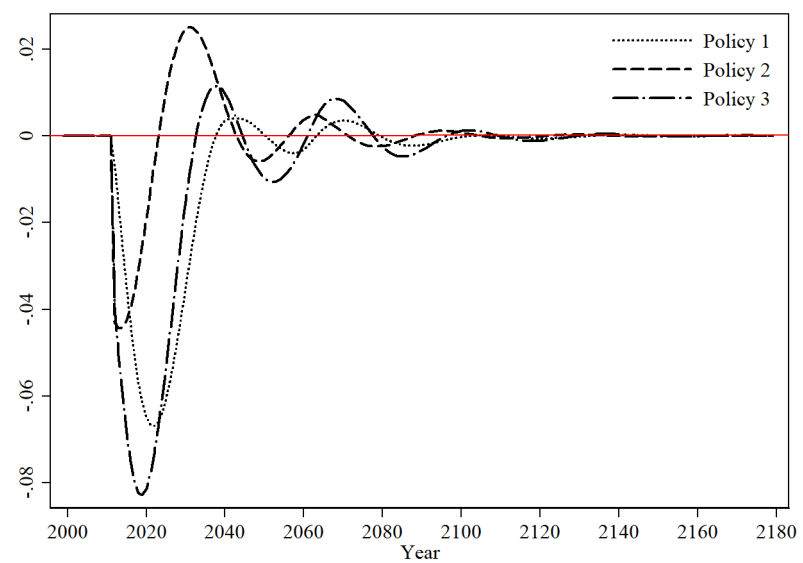

(f) Debt share in GDP: relative to baseline

Note: results from a voting round in 2012. The results for the other rounds are available upon request. Differences relative to the baseline are expressed in percentage points. Policy 1 is a permanent shift of the contributions from the capital pillar to the PAYG pillar. Policy 2 is a one-off capturing of the assets accumulated in the capital pillar. Policy 3 combines Policy 1 and Policy 2. 
Figure D.8: Adjustments in capital $K_{t}$ (left) and labor supply $L_{t}$ (right)
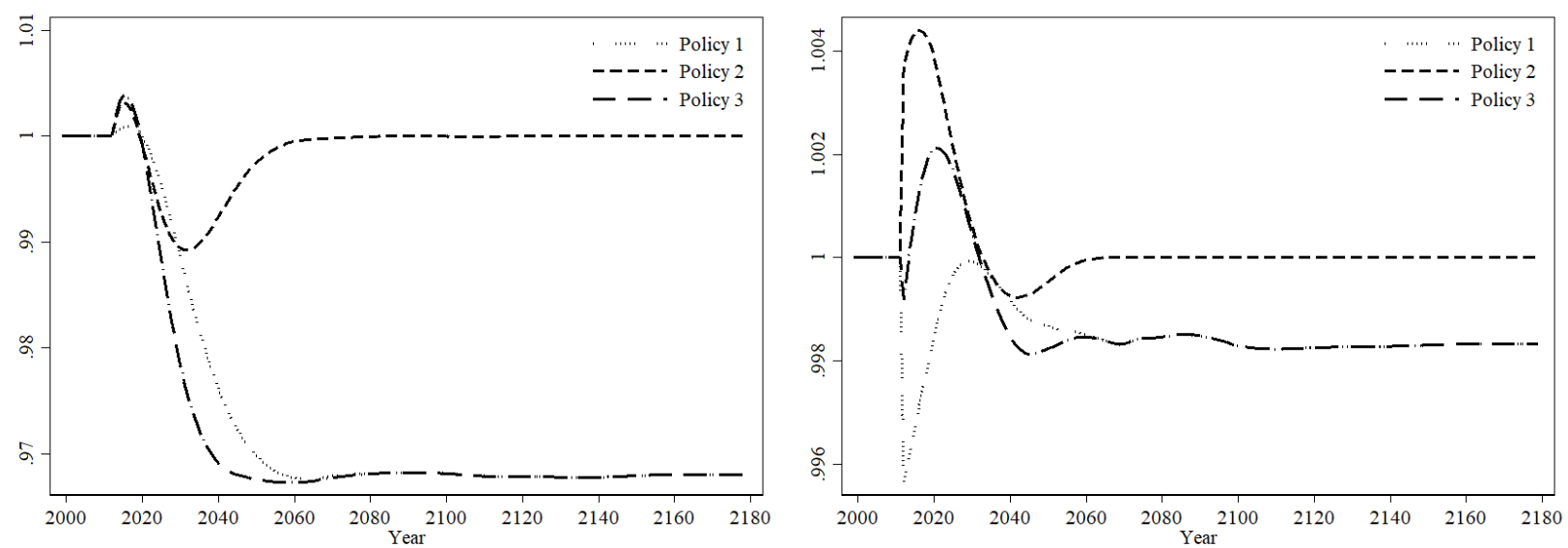

Notes: measures expressed in terms of ratio relative to baseline. Reported are the results from the vote in 2012. The results for other voting years are available upon request.

Figure D.9: Adjustments in the interest rate $r_{t}$ (left) and the wage rate $w_{t}$ (right)
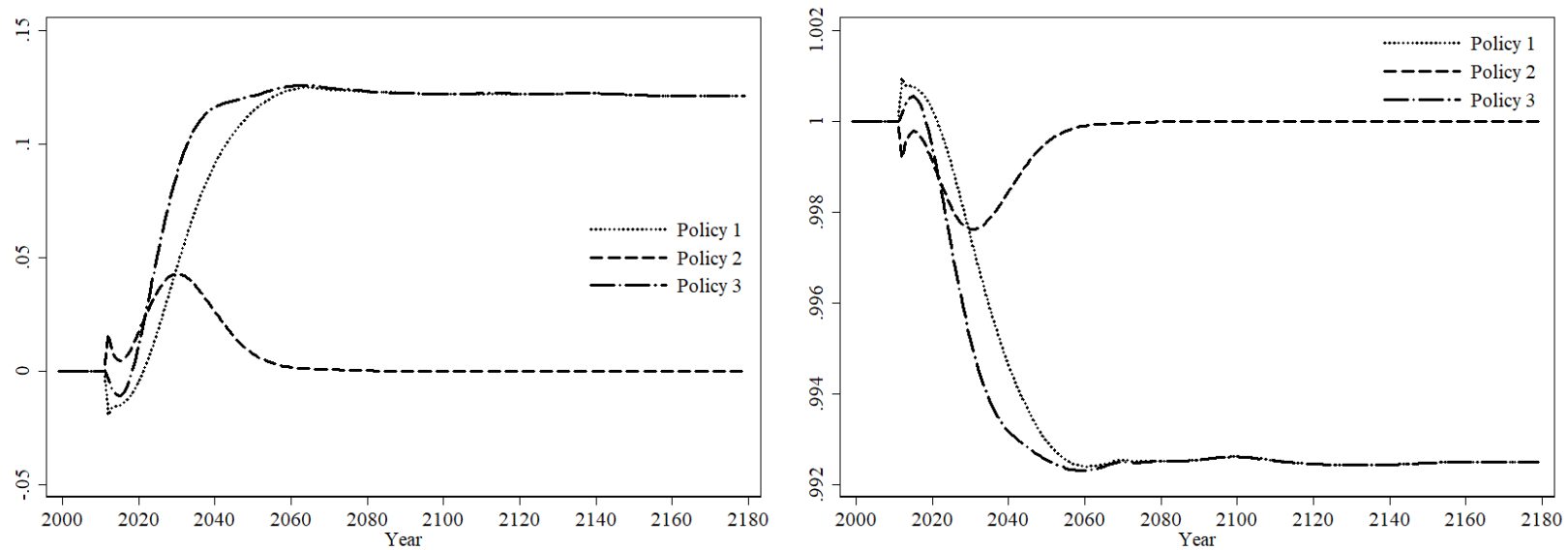

Notes: the interest rate is expressed as the difference relative to the baseline (in percentage points). The wage rate is expressed as a ratio relative to the baseline. Reported are the results from a vote in 2012. The results for other voting years are available upon request. 


\section{E The effects on poverty}

We also show the aggregate effects on both absolute and relative poverty. We define relative poverty as consumption below $60 \%$ of the current median consumption. We define absolute poverty as consumption below $60 \%$ of consumption in the initial steady state. Notice that all the variables in the model are made stationary. Hence, this measure is not affected by population change and exogenous technological progress. The evolution of the poverty measures is displayed in Figure E.10.

Figure E.10: Evolution of poverty

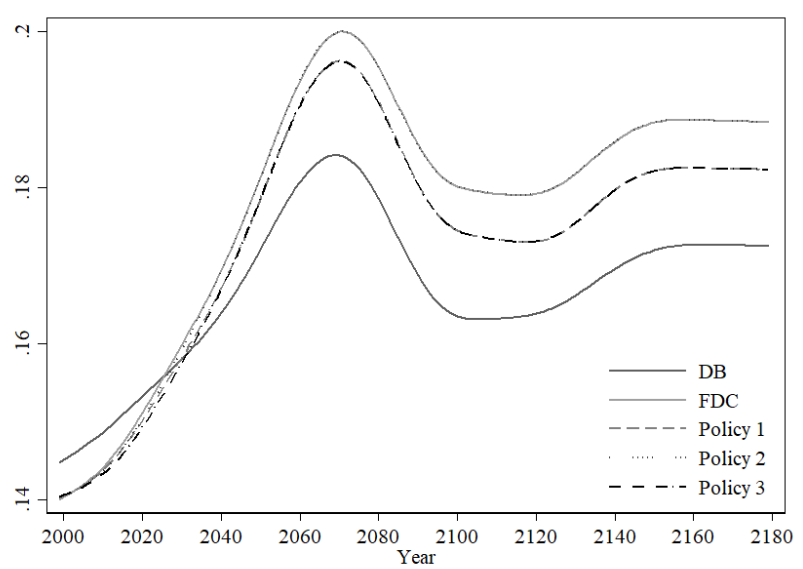

(a) relative poverty: all

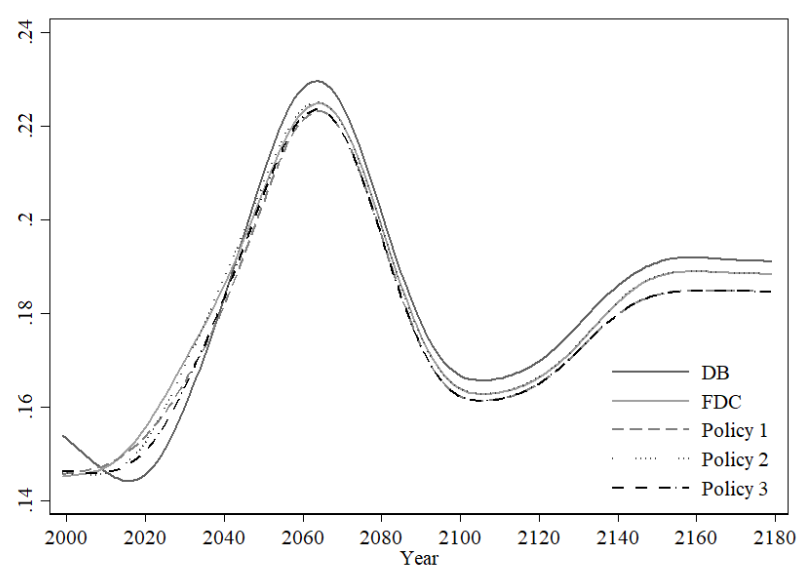

(c) absolute poverty: all

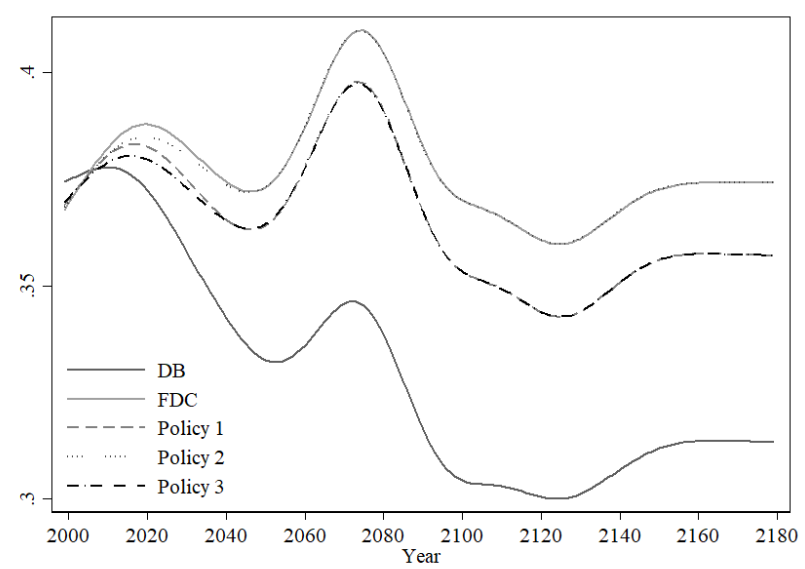

(b) relative poverty: elderly

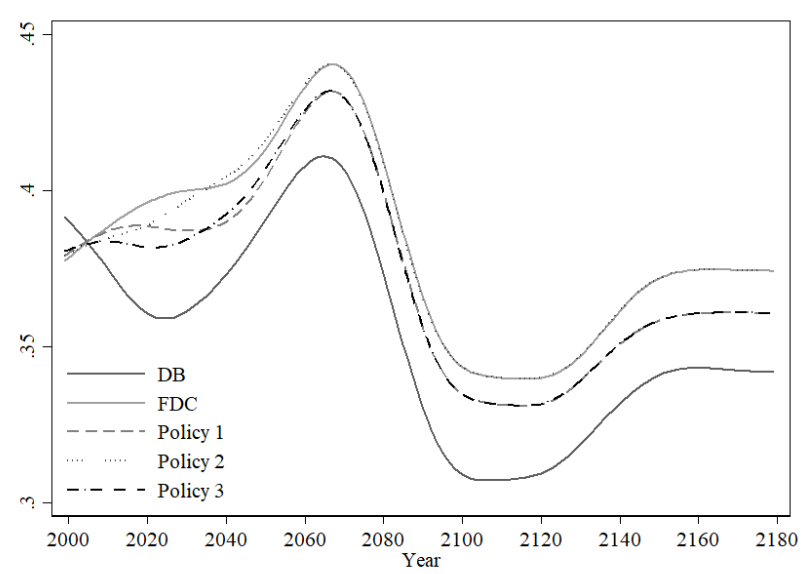

(d) absolute poverty: elderly

Note: relative poverty is defined as the fraction of the population with consumption below $60 \%$ of median consumption, while absolute poverty is defined as the fraction of the population with consumption below $60 \%$ of median consumption in the initial steady state. Old-age poverty measures the fraction of poor elderly as a share of the total group of elderly. Policy 1 is a permanent shift of the contributions from the funded pillar to the PAYG-DC pillar. Policy 2 denotes a one-off capturing of the assets accumulated in the funded pillar. Policy 3 combines Policies 1 and 2.

Poverty would increase the least if the PAYG-DB system was continued. This is because the majority of the poor households are in old-age: the higher pension benefits under PAYG-DB system imply that a larger fraction of them can afford sufficient consumption. Moreover, the higher consumption tax under this system implies lower average consumption, hence fewer households falling below the poverty threshold. Naturally, as longevity stops increasing, pensions level off, and no further tax 
adjustment is needed. Hence, also poverty levels off.

Lowering of the pensions due to replacing the DB pension formula with a DC pension formula raises the share of old-age households that cannot afford consumption above $60 \%$ of the median. Moreover, DC allows pension systems to be balanced and hence lowers taxation of consumption. The higher level of consumption further raises the share of old-age households that cannot afford consumption above the threshold.

The direct consequence of the asset capture is the decline of overall consumption, relative to the no asset capture scenario. This yields a decline in the poverty measures. However, this decline is mostly driven by lowering the threshold above which a household is no longer defined as poor, not by increased consumption among these households. 